\title{
Mediators of the Disparities in Depression Between Sexual Minority and Heterosexual Individuals: A Systematic Review
}

\author{
Angeliki Argyriou' ${ }^{1} \cdot$ Kimberley A. Goldsmith $^{2} \cdot$ Katharine A. Rimes $^{1}[$
}

Received: 12 January 2020 / Revised: 18 September 2020 / Accepted: 7 October 2020 / Published online: 10 March 2021

(c) The Author(s) 2021

\begin{abstract}
Evidence suggests that sexual minorities (e.g., those identifying as lesbian, gay, or bisexual) experience increased rates of depression compared to heterosexual individuals. Minority stress theory suggests that this disparity is due to stigma experienced by sexual minorities. Stigma processes are proposed to contribute to reduced coping/support resources and increased vulnerability processes for mental health problems. This review provided a systematic examination of research assessing the evidence for mediating factors that help explain such disparities. A literature search was conducted using the databases PubMed, PsycINFO, and Web of Science. The review included 40 identified studies that examined mediators of sexual minority status and depressive outcomes using a between-group design (i.e., heterosexual versus sexual minority participants). Studies of adolescents and adult samples were both included. The most common findings were consistent with the suggestion that stressors such as victimization, harassment, abuse, and increased stress, as well as lower social and family support, may contribute to differing depression rates in sexual minority compared to heterosexual individuals. Differences in psychological processes such as self-esteem and rumination may also play a role but have had insufficient research attention so far. However, caution is needed because many papers had important methodological shortcomings such as the use of cross-sectional designs, inferior statistical analyses for mediation, or measures that had not been properly validated. Although firm conclusions cannot be drawn, the current evidence base highlights many factors potentially suitable for further exploration in high-quality longitudinal research or randomized studies intervening with the potential mediators.
\end{abstract}

Keywords Sexual minority $\cdot$ Sexual orientation $\cdot$ Depression $\cdot$ Mediation $\cdot$ LGB

\section{Introduction}

\section{Sexual Minorities and Depression}

Systematic reviews have reported that compared to heterosexual people, sexual minority individuals (e.g., those identifying as lesbian, gay, or bisexual) have elevated rates of mental health problems and are as much as four times more likely to attempt suicide (King et al., 2008; Plöderl \& Tremblay, 2015). A strong link has been consistently demonstrated

Katharine A. Rimes

katharine.rimes@kcl.ac.uk

1 Department of Psychology, Institute of Psychiatry, Psychology and Neuroscience, King's College London, De Crespigny Park, London SE5 8AF, UK

2 Department of Biostatistics and Health Informatics, Institute of Psychiatry, Psychology, and Neuroscience, King's College London, De Crespigny Park, London, UK between sexual minority status and depression in particular (e.g., Bostwick et al., 2010; Chakraborty et al., 2011; Pakula \& Shoveller, 2013). A meta-analysis found that the risk of 12-month prevalence of depression in sexual minority individuals was at least twice that of heterosexual controls (King et al., 2008). Similar differences in prevalence rates have been found for heterosexual versus sexual minority youth (e.g., Marshal et al., 2011), suggesting that disparities in depression may appear early in life.

Robust research evidence about the mechanisms through which such disparities come about would be both theoretically and clinically valuable. For example, the identification of intermediate factors that contribute to elevated rates of depression in this population would be instrumental for designing and refining effective prevention programs that would help protect at-risk LGB individuals and developing targeted therapeutic approaches for sexual minority people who experience depression. 
Minority stress theory has been one of the main theoretical frameworks used to explain the differences in the rates of depression and other mental health problems between sexual minorities and heterosexuals (Meyer, 2003). According to the theory, being a member of a minority group exposes individuals to discrimination, stigma, and prejudice. Such exposure creates a stressful social environment which contributes to the presence of mental health problems. Meyer suggested that such minority stressors may be distal (external to the person) or proximal, i.e., internal processes about how the individual relates to their identity. Distal stressors include prejudice events such as discrimination and violence, while proximal events include sexual minority-specific internalized stressors such as internalized homophobia, expectations of rejection, and concealment stress. Indeed, evidence indicates that sexual minority individuals face multiple stressors, often starting early in their lives, including peer victimization, physical assault, abuse, and rejection from family and friends (e.g., Balsam et al., 2005; Corliss et al., 2002). There is also a lot of research demonstrating that sexual minority individuals experience a multitude of internal minority stressors such as perceived stigma and expectations of rejection and discrimination, stress about disclosure and concealment, and internalized negative attitudes about their sexual identity (see Meyer, 2003 for a review).

Hatzenbuehler (2009) expanded on minority stress theory by suggesting that the increased stress that sexual minority individuals are exposed to is likely to increase the likelihood of general maladaptive cognitive processes, unhelpful coping and emotion regulation strategies, and reduced social support, all of which may in turn increase the risk for mental health problems. While Meyer's work focused on the distal and external stressors that sexual minorities experience as well as the sexual minority-specific proximal factors such as internalized homophobia, Hatzenbuehler's framework shifted the focus to the intermediate cognitive, regulatory, and social mechanisms through which minority stressors lead to mental health problems, including depression. Furthermore, Hatzenbuehler emphasized the importance of examining whether general psychological processes that are known vulnerability factors in the general population are heightened in sexual minorities and whether they can therefore help explain the increased prevalence of mental health problems in sexual minorities compared to heterosexuals.

\section{Mediation Analysis}

In order to understand the intermediate factors that explain the causal relationship between sexual orientation and depression, it is important to look at research that examines mediating variables. Mediation is a process whereby an independent variable is thought to cause change in an intervening variable which in turn causes change in the dependent variable (Lockwood et al., 2002; MacKinnon et al., 2002). In this sense, a hypothesized mediation model will generally constitute a causal chain of events; the plausibility of each of these causal relationships needs to be considered and justified. It follows that a key assumption in mediation analysis is temporal ordering, given that causal relationships are being hypothesized (Cole \& Maxwell, 2003). The causal chain described above implies that the independent, mediator, and dependent variables should be measured separately in an ordered fashion in time. Therefore, studies measuring these variables longitudinally are generally considered methodologically superior.

A review of research examining mediators should include the evaluation of the robustness of statistical methods used for mediation analysis. Indeed, several considerations need to be made in assessing the quality of such methodology: Statistical methodology on mediation analysis has developed significantly since the causal steps approach to mediation was developed by Baron and Kenny (1986), including the idea that if mediation is hypothesized, it is still important to do a mediation analysis even in the absence of an effect of the independent on the dependent variable (Emsley et al., 2010; Goldsmith et al., 2018a; MacKinnon \& Dwyer, 1993). Mediation analyses now generally focus on a product of coefficients mediated effect (a path $\mathrm{x} b$ bath), which can be estimated efficiently in one step using the structural equation modeling (SEM) framework, tests of the joint significance of $a$ and $b$ paths, and the Sobel test of significance of the indirect effect and bootstrapping to calculate mediated effect confidence intervals (Goldsmith et al., 2018b; MacKinnon, 2001; MacKinnon et al., 2004; Sobel, 1982). In addition, in recent years, mediation analysis has focused on sources of bias, such as confounding; researchers should adjust for baseline mediator and outcome measures and include all important potential confounders of the relations in the mediation models (Dunn et al., 2013; Goldsmith et al., 2018a; Imai et al., 2010; Pickles et al., 2015; VanderWeele \& Vansteelandt, 2009).

\section{The Current Study}

In recent years, research has investigated factors contributing to the mental health disparities between heterosexual and sexual minority youth and adults by looking at mediators of the relation between sexual orientation and depressive symptomatology. Examining mediators can help us better understand the mechanisms through which both sexual minority status and the stigma associated with it confer risk for depression (Hatzenbuehler, 2009). Moreover, assessing the quality of statistical methodology and design (e.g., temporal ordering of variables) that the literature has used to test mediation is important in drawing conclusions about which mediators are causally contributing to the development of depression in sexual minorities. This would help provide robust evidence 
for appropriate targets for prevention and intervention that would help end disparities between sexual minorities and their heterosexual peers. No study to date has systematically reviewed between-group studies that use mediation analysis to examine evidence regarding different psychosocial factors that may explain the differences in rates of depression between heterosexual and sexual minority individuals.

Therefore, the aim of the present study is to identify the factors that mediate the relation between sexual minority status and depressive symptoms by systematically reviewing research studies in the literature that use mediational approaches to investigate the disparities among heterosexual and sexual minority individuals. The study also reports the theoretical models used to derive the hypotheses tested in the included studies.

\section{Method}

Prior to data extraction, the review was registered with PROSPERO (registration number CRD42017079383). The review was conducted using PRISMA guidelines for systematic reviews (Moher et al., 2009).

\section{Data Sources and Search Strategy}

A search of published studies was conducted using the following electronic databases: PsycINFO, PubMed, and Web of Science. The search term was: (LGBT OR sexual minorit* OR sexual orientation OR gay OR lesbian OR bisexual OR queer OR homosexual* OR LGB OR non-heterosexual) AND (Heterosexual* OR non-minority) AND (depress* OR mood) AND (mechanism* OR mediat* OR predict* OR factor* OR explain OR caus* or risk factor or structural equation model*). Additional studies were retrieved by crossreferencing of selected articles, and through hand searches. The literature search was completed on October 27, 2017, and was updated on October 21, 2019.

\section{Inclusion and Exclusion Criteria}

We included studies that: (1) were published in peer reviewed journals; (2) included a statistical group comparison between heterosexual and sexual minority status individuals; (3) used a measure of depressive symptoms or a diagnosis of depression as an outcome variable; (4) used analyses that tested hypothesized mediation effects with sexual orientation as the independent variable and depression as the dependent variable. We excluded studies that: (1) were non-empirical (reviews or theory papers); (2) did not have the full description of the study available (e.g., conference abstracts); (3) were published in languages other than English. We did not exclude studies based on publication year, sample size, age groups used, or whether they used a subsample of the population of interest. An initial screening of all title and abstracts returned using the aforementioned search strategy was conducted by the first author. A second independent reviewer also screened a random $10 \%$ of the titles and abstracts returned. Studies that met the eligibility criteria based on the initial screening were screened using the full-text papers by the first author and a subgroup were also screened by an independent reviewer. The kappa statistic was used to measure inter-rater agreement.

\section{Data Extraction}

The following data were extracted from included studies: study title; authors; year; design (cross sectional or longitudinal); country/setting; population/sample characteristics; recruitment strategy; total and group sample size; sexual orientation measure; hypothesized mediator(s); measure(s) for mediator(s); depression measure; confounders; type of mediation analysis (series of regression or SEM); test of significance for mediation; statistical analysis details; main findings; and limitations. As studies were methodologically and statistically heterogeneous, a meta-analysis or other methods of statistical pooling to synthesize the findings were not appropriate. The theoretical models, methodology, results, and limitations of the studies are therefore qualitatively summarized in the Results and Discussion sections, with much supporting detail provided in the tables and the Appendix. This process was conducted mainly by authors AA and KAR, with statistical expertise provided by KAG.

\section{Quality Assessment}

A quality assessment measure developed for treatment mediation studies by Lubans et al. (2008) and expanded in other studies (Cerin et al., 2009; Lee et al., 2015; Mansell et al., 2013) was further adapted for the purposes of this study. This included four additional items being added from the Quality Assessment Tool for Observational Cohort and Cross-Sectional Studies (US Department of Health and Human Services, 2014) and the Quality Assessment Tool for Quantitative Studies (Effective Public Health Practice Project, 2009) to address the methodological quality of the predictor, sampling procedures, representativeness, and response/uptake. The quality assessment focused on the mediation hypotheses of the studies that were relevant to this review. A score for each study was computed by assigning a value of 0 (no) or 1 (yes) to each of 12 questions listed in Table 1. If a study did not explicitly report information related to an item, it was assigned 0 for that item. A total score was calculated by summing the scores of the 12 items for each of the studies. Studies which scored $0-4$ were classified as of poor quality, 5-8 were classified as of fair quality, and 9-12 were classified as 
Table 1 Quality assessment tool

Item:

1. Did the study cite a theoretical framework?

2. Was the independent variable clearly defined, valid (face validity), and reliable, and implemented consistently across participants?

3. Were the psychometric characteristics of the mediator variable reported and were they within accepted ranges? (Computed from the present study or a reference provided)

4. Were the psychometric characteristics of the depression variable reported and were they within accepted ranges? (Computed from the present study or a reference provided)

5. Did the study report a power calculation? If so, was the study adequately powered to detect mediation?

6. Were statistically appropriate/acceptable methods of data analysis used? ${ }^{\mathrm{a}}$

7. Did the study ascertain whether changes in the mediating variable preceded changes in the outcome variable?

8. Did the study ascertain whether changes in the predictor variable preceded changes in the mediator variable?

9. Did the study control for possible confounding factors?

10. Were all the subjects selected or recruited from the same or similar populations (including the same time period)? Were inclusion and exclusion criteria for being in the study prespecified and applied uniformly to all participants?

11. Are the individuals selected to participate in the study likely to be representative of the LGB and heterosexual population?

12. (a) Was $80 \%$ or more of potential participants included at point of relevant analyses?

(b) If the study was longitudinal, was loss to follow-up after baseline $20 \%$ or less?

${ }^{\text {a }}$ Studies were assigned 1 if they conducted and reported a test of significance for the mediated effect either through testing of the product of coefficients (e.g., Sobel test, bootstrapping) or joint testing of the a and b paths (MacKinnon et al., 2002). Studies were assigned a 0 if they solely used the causal steps approach (Baron \& Kenny, 1986) or other approaches to mediation without testing for statistical significance of the indirect effect

of good quality. For item 6 (statistically appropriate/acceptable data analysis methods), studies were assigned 1 if they conducted and reported a test of significance for the mediated effect either through testing of the product of coefficients (e.g., Sobel test, bootstrapping) or joint testing of the a and b paths, as recommended by MacKinnon et al. (2002). Studies were assigned a 0 if they solely used the causal steps approach (Baron \& Kenny, 1986) or other approaches to mediation such as SEM without testing for statistical significance of the indirect effect. Quality assessment ratings were done by two raters. Inter-rater reliability was substantial $(\kappa=.782)$, and discrepancies were resolved through discussion.

\section{Results}

\section{Included Studies}

The searches identified 1397 studies, 547 of which were duplicates. Of the remaining 850 studies, 716 were excluded based on the title or the abstract when it was evident that they either did not meet the inclusion criteria or at least one of the exclusion criteria. Information about the relevant inclusion and exclusion criteria for the studies excluded in the first stage of the screening was not recorded. The number of fulltext articles assessed for eligibility was 134 . Inter-rater agreement about decisions to include studies or not was very good, $\kappa=.939(95 \%$ CI 0.87, 1.00). Discrepancies were resolved through discussion relevant to the inclusion and exclusion criteria. The final number of studies meeting the inclusion and exclusion criteria and therefore included in the review was 40. Figure 1 illustrates the flow of studies.

\section{Quality Assessment}

The results of the quality assessment are shown in Table 2 . Most studies were rated as having fair methodological quality. Five studies were rated as being of good quality and seven studies rated as being of poor methodological quality.

\section{Study Characteristics}

Study characteristics are summarized in Table 3 . Of the 40 studies, 28 had a cross-sectional design and 12 had a longitudinal design. The longitudinal studies either measured sexual orientation and mediator at time 1 and depression at time 2 or sexual orientation at time 1 and mediator and depression at time 2, with none of the studies collecting measures of the three variables at three different time points. Most of the studies took place in the U.S. $(n=26)$, while some took place in Australia $(n=5)$, Sweden $(n=2)$, the UK $(n=1)$, the Netherlands $(n=1)$, China $(n=1)$, Canada $(n=1)$, Israel $(n=1)$, and Nigeria $(n=1)$. One study took place in both the U.S. and Canada. 
Fig. 1 Study flow diagram

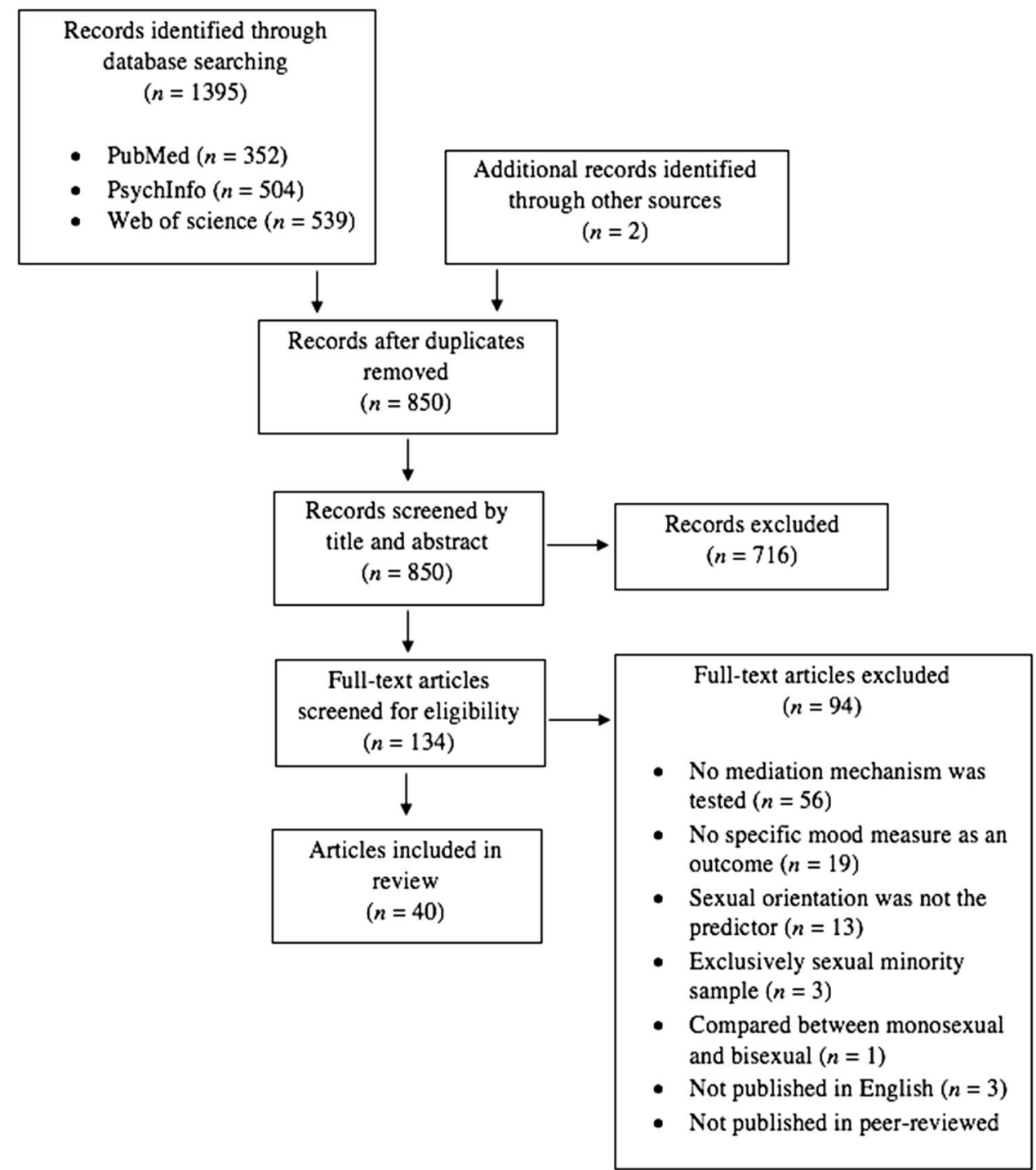

\section{Population}

Information about the sample is provided in Table 3 with additional information in the Appendix. Although a few studies did not provide a specific age range, of the 40 studies, 13 seemed to have had predominantly early to late adolescent samples (11 to 19 years), 14 had young adult or university student samples (17 to 29 years), 11 used exclusively adult samples (18 years and over), while one study used both a young adult and an older adult cohort and another study used young adult and mid-adult sample. Some of the studies used subsamples of the population, such as sexual assault survivors, victims of intimate partner violence, or exclusively Black American participants. Some studies used other samples that may limit the generalizability of their findings, including samples of twin siblings, children of registered nurses, medical students, and undergraduate psychology students. Several studies used the same or overlapping samples, and it is therefore not possible to report an overall number of participants investigated across the included papers.

\section{Theoretical Framework}

Many of the studies derived their research questions from broader theoretical frameworks relating to sexual minority individuals' increased exposure to social stress, with the most often-cited theory being minority stress theory (Meyer, 2003). A few studies cited Hatzenbuehler's (2009) psychological mediation framework that includes more general mechanisms through which exposure to social stressors renders sexual minorities more vulnerable to mental health problems. Similarly, other studies explored general psychosocial processes that have been established as risk factors in the general population and sought to explore their specific associations with sexual minority 


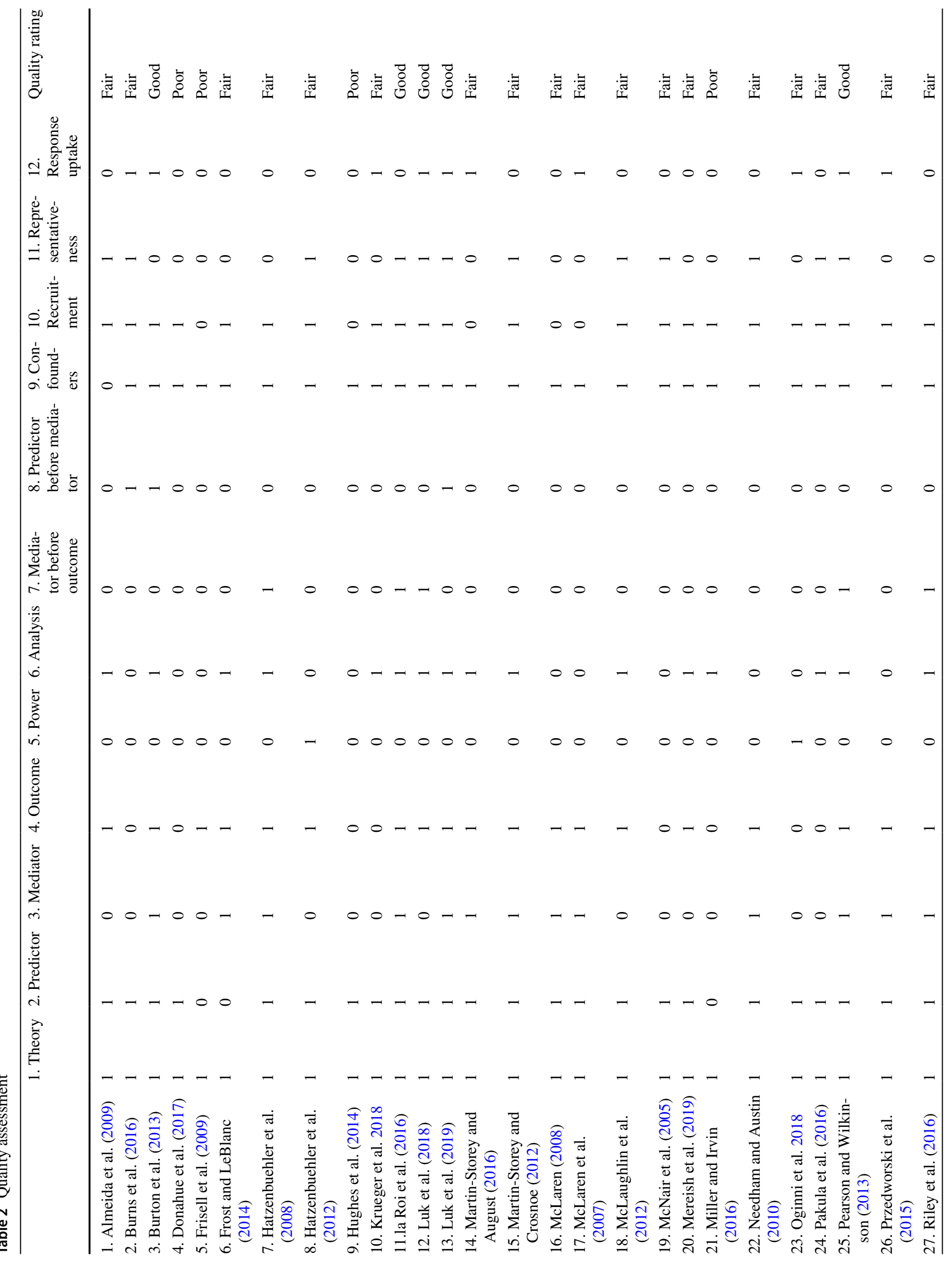




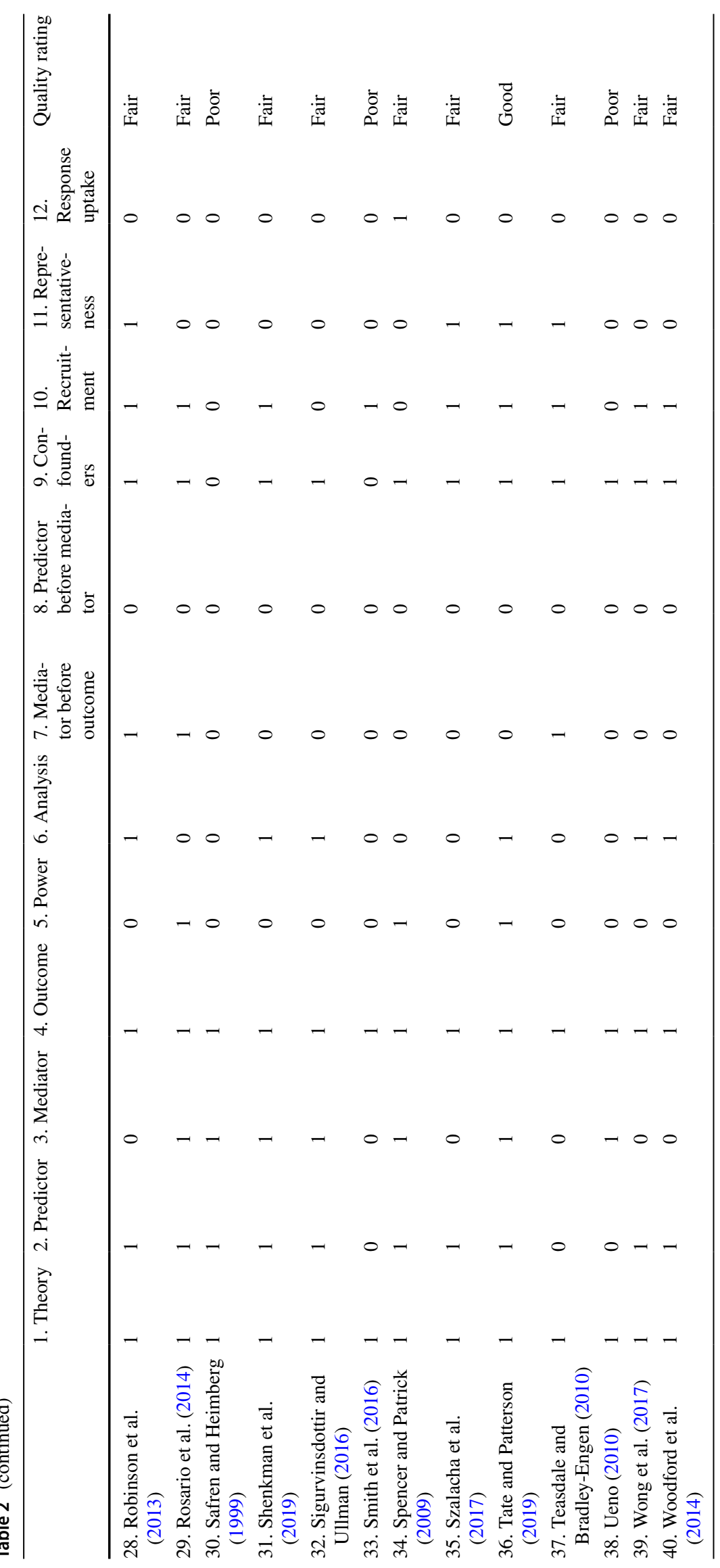




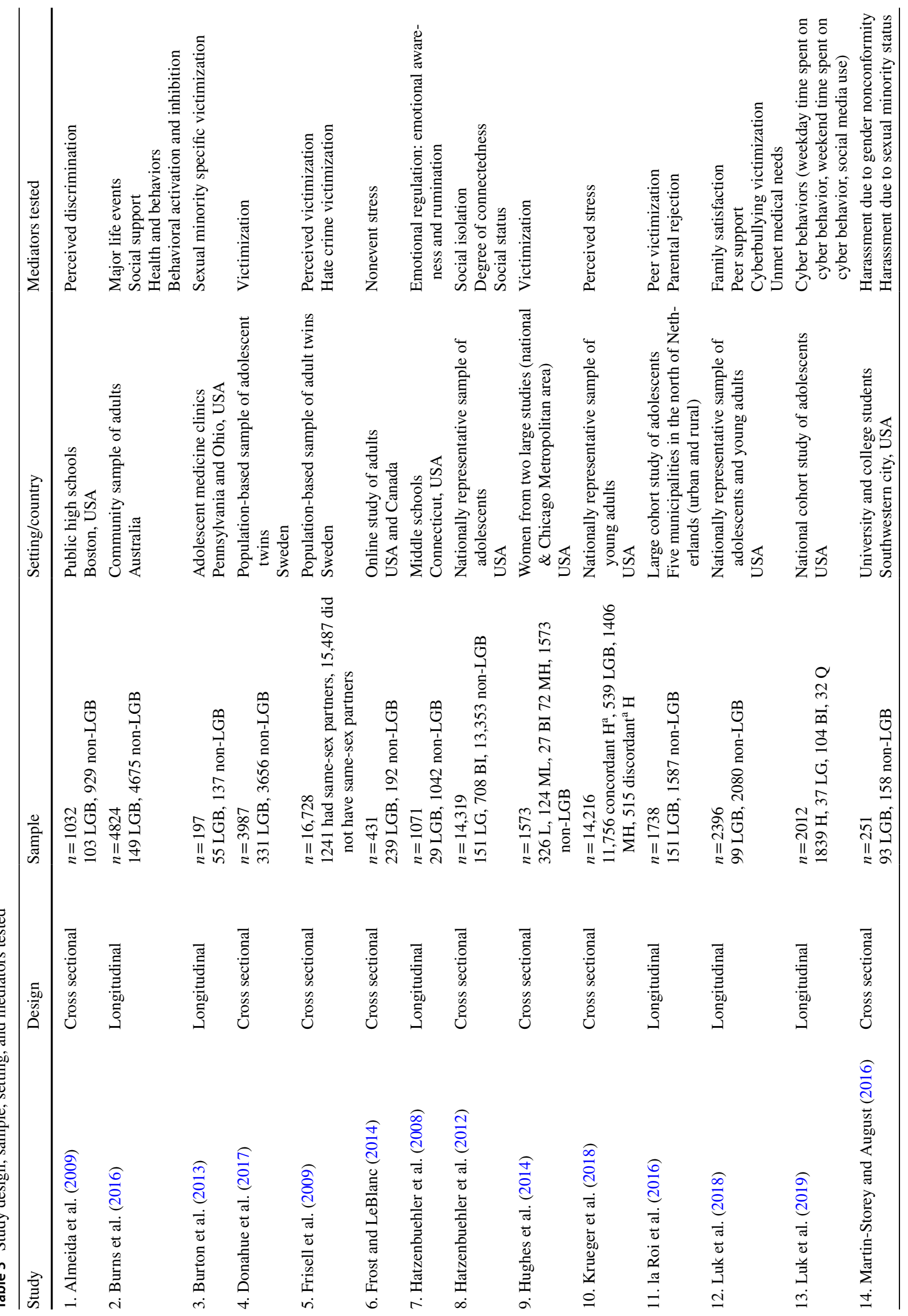




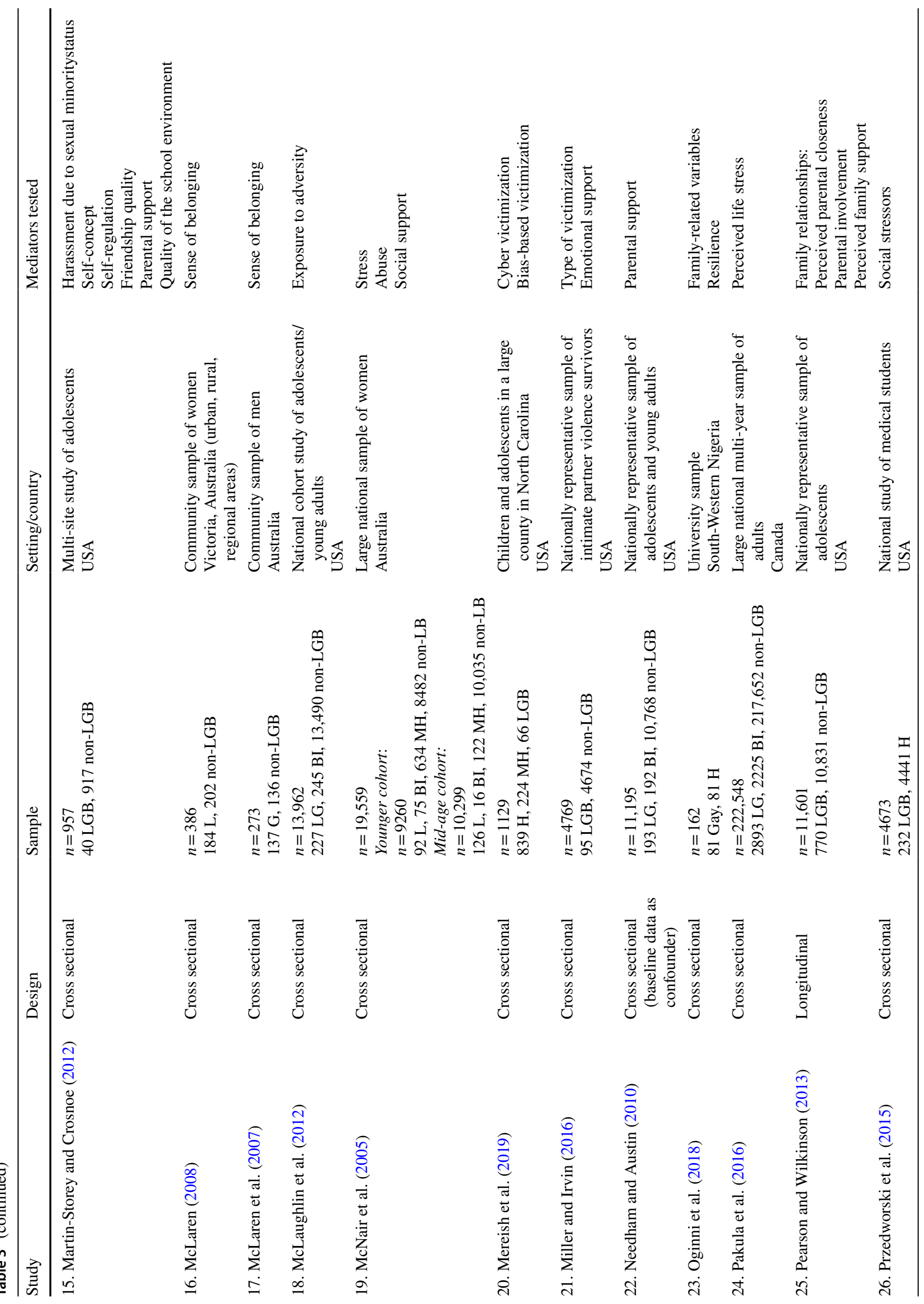




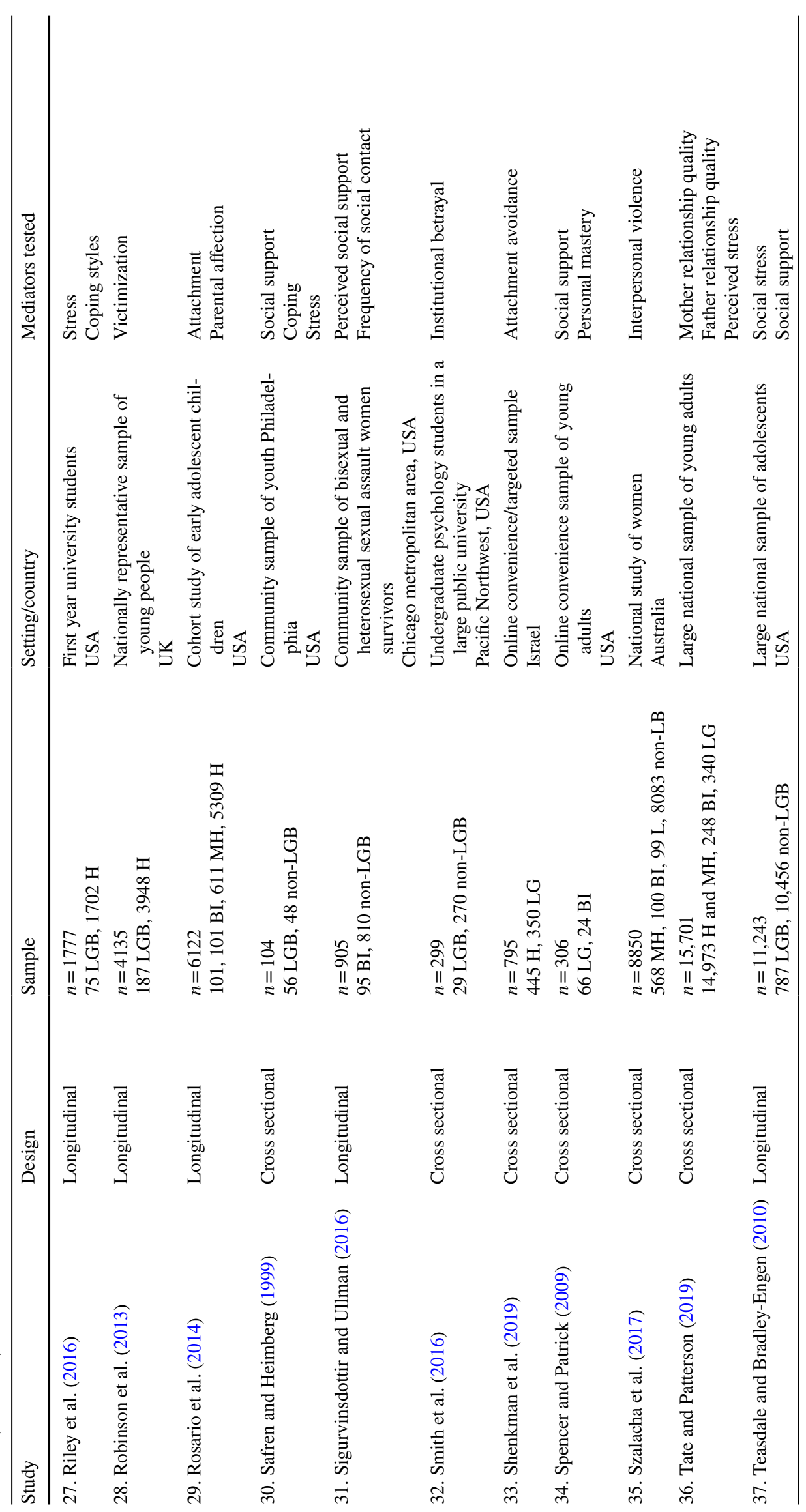




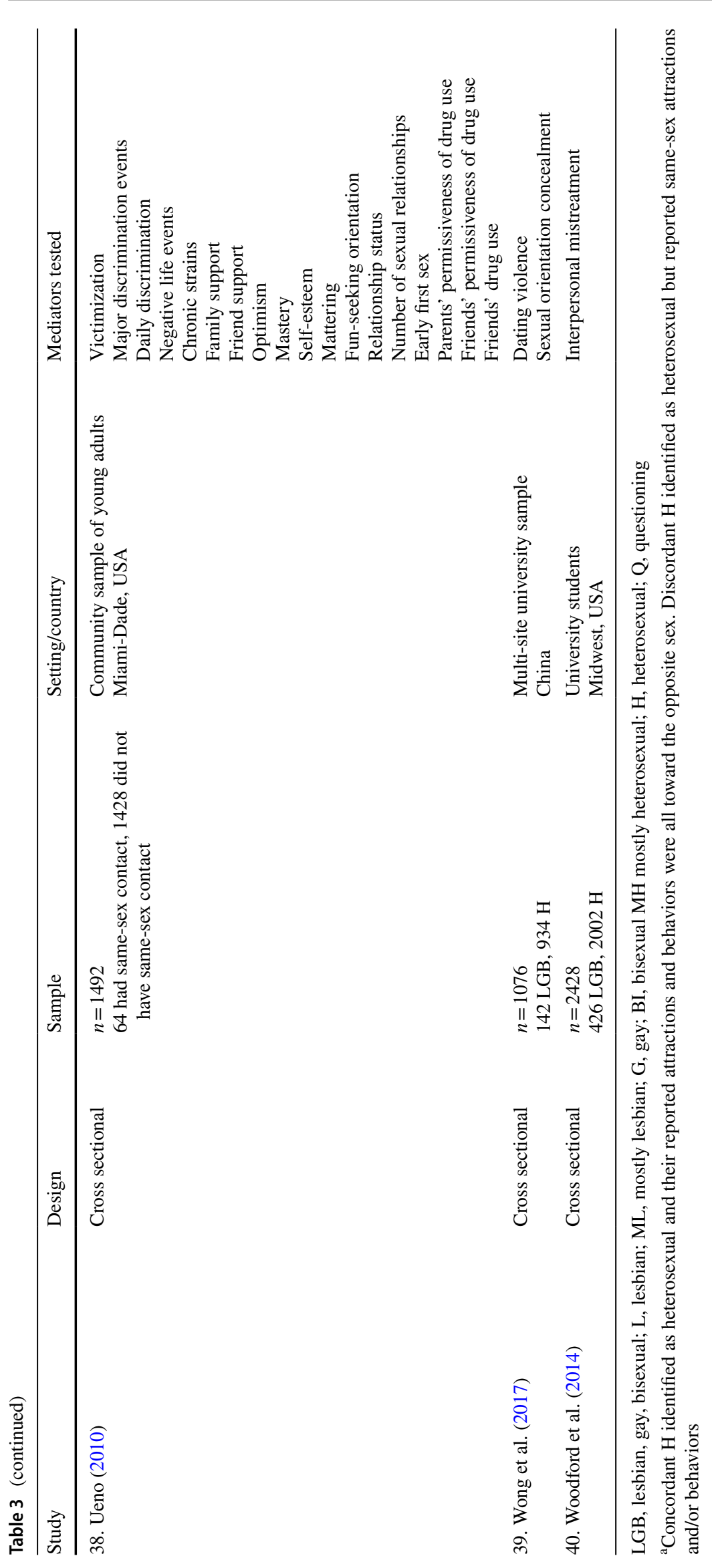


identity. Specific hypotheses pertaining to the sexual orientation disparities in mental health problems investigated in other studies included: the role of unmeasured genetic and shared environmental factors; the differential incidence and impact of sexual and physical violence in sexual minority populations; the interacting role of gender/sex and sexual orientation; childhood adversity; cultural-specific factors associated with concealment of sexual orientation; theory of human relatedness and social belonging (Hagerty et al., 1993); and the importance of family support and attachment for this population.

\section{Measurement of Sexuality}

Sexuality was assessed in a number of ways. Most studies used sexual identity or sexual orientation questions and response options. Seven studies asked about sexual or romantic attraction, and one asked about preference for romantic partners. One study asked about the gender of individuals with whom participants were in relationship and two studies inquired about the number of the same-sex and the opposite-sex people respondents had sexual intercourse with. A study asked both about identity and behavior, while another study averaged the responses from three items asking about fantasies, attraction, and behavior. One of the studies asked about identity but encompassed behavioral indicators in the response options (e.g., homosexual with some heterosexual experience). Two studies did not report how they assessed sexuality.

Sexuality-related response options available also varied greatly with studies using from three to seven categories of sexuality, and one study using a fill-in-blank response. Most studies categorized sexual minority and heterosexual individuals into two groups, with some citing power concerns as the reason they did not distinguish among more sexual minority groups. Studies often included response categories such as mostly homosexual, mostly heterosexual, other, and questioning, but they varied on how they later treated these responses. For example, while some of the studies included participants who selected mostly heterosexual in the sexual minority group, two studies categorized them as a distinct group, another study placed them in the heterosexual group despite having a bisexual category in their analysis, and another study excluded them from the analysis. Similarly, participants who chose other were either placed in the sexual minority group or were excluded from the analysis. Individuals attracted to neither males or females, not sure, and with no sexual experience were excluded from the analyses, while two studies that included a questioning response, placed the participants selecting it in the sexual minority group. Finally, three studies excluded participants who identified as bisexual from their analyses.

\section{Outcome Measures}

Most studies used validated self-report measures of depressive symptoms including the Center for Epidemiological Studies Depression (Kohout et al., 1993; Radloff, 1977); the Beck Depression Inventory II (Beck et al., 1996); the Depression Anxiety Stress Scales (Lovibond \& Lovibond, 1995); the Modified Depression Scale (Orpinas, 1993); the Youth and Adult Self-Report (Achenbach \& Rescorla, 2001, 2003); the Zung Depression Scale (Zung, 1965); the Hospital Anxiety and Depression Scale (Chinese version; Leung et al., 1993); the Brief Symptom Inventory (Derogatis, 1993); the Goldberg Depression \& Anxiety Scale (Goldberg et al., 1988); the PROMIS Emotional Distress-Depression scale (Pilkonis et al., 2011); and the Children's Depression Inventory (Kovaks, 1992). Two studies used items the authors validated as a scale or as a latent variable for the purposes of their study. One study used diagnostic interview questions to code participants as having or not having depression. Some studies asked questions that had not been validated regarding the presence of a diagnosis of depression and then used them to classify participants as having or not having depression. One study used both a self-report measure and questions about history of depression as outcomes, while another study used both the Structured Clinical Interview (SCID) and a self-report measure. Finally, one study used a single-item depression measure as well as a validated questionnaire.

\section{Mediators}

Mediators investigated can be found in Table 3, while details about the measures used for the mediators can be found in the Appendix. Only three studies assessed the independent variable at an earlier time point than the mediator, and eight studies assessed the mediator before the outcome. Half of the studies used measures of the proposed mediators for which evidence of validity and reliability was limited or not provided. Most studies used one or two mediators in their analysis, while others analyzed multiple mediators. A few of the studies used a mediator assessed by a single question not associated with a validated scale. Included studies used a variety of variables as hypothesized mediators of the association between sexual minority status and depression.

Many studies looked at self-reports of victimization, harassment, discrimination, or abuse as mediators, either relating to sexual minority status or more generally. Other, more general, stress-related mediators included major life events or chronic stress. Some studies investigated sex, relationship, friendship, or family-related mediators. Other social factors tested included social support, the quality of the school environment, sense of belonging, and institutional betrayal. Intrapersonal factors investigated as mediators included 
emotional regulation, self-regulation, coping styles, resilience, self-concept, and mastery.

\section{Confounders}

The overwhelming majority of studies controlled for some confounders with most studies controlling for sociodemographic variables (e.g., age, sex or gender, ethnicity/race, place of residence, education, income, family structure, relationship status). Only a few studies controlled for baseline levels of depression. A few studies also controlled for familial confounding (confounding caused by shared environmental/ genetic risk factors) by comparing participants to siblings or controlling for parental psychopathology. One of the studies included history of adverse childhood experiences as a confounder, while three studies controlled for violence and victimization. One study controlled for social desirability, and another study that used different recruitment methods included recruitment method as a confounder. A minority of studies did not use any confounders.

\section{Statistical Analysis}

The statistical approaches undertaken in the papers are shown in Table 4. Only five studies reported power calculations. With regard to data analytic approaches, many of the studies followed mediation procedures similar to the causal steps approach proposed by Baron and Kenny (1986), while some of the studies used SEM. Many of the studies did not conduct a test for the mediated effect either through testing the significance of the product of coefficients estimate of the indirect effect, or joint testing of the $a$ and $b$ paths.

\section{Study Findings}

The key findings of each study can be found in Table 4, and the findings are also summarized below.

\section{Discrimination and Victimization}

Many of the studies explored victimization-related mediators. Perceived or actual sexual orientation-specific discrimination was found to be a mediator in three American adolescent samples, while peer victimization was found to be a mediator in longitudinal studies with young people in the UK and the Netherlands. Bias-based victimization was also demonstrated to be a mediator in a sample of Black American youth. Cyberbullying victimization was found to be a significant mediation in a longitudinal youth sample and in a Black American youth sample. Furthermore, victimization and daily discrimination attenuated the relation between same-sex contact and depressive symptoms in a cross-sectional young adult sample.
One of the studies found that incivility and heterosexist harassment mediated the relation between sexual minority status and depression in university students. However, in another university sample, the association between sexual minority status and depression was mediated by harassment due to gender nonconformity but not harassment due to sexual minority status. Furthermore, in two studies that controlled for additional factors, the role of victimization as a mediator was reduced: perceived and hate-crime victimization attenuated the association between sexual orientation and depression in a Swedish adult sample; however, when controlling for familial confounding, depression differences between heterosexual and sexual minority participants were smaller, albeit still statistically significant for women. Similarly, the effect of sexual minority status on depressive symptoms was largely attenuated when controlling for unmeasured familial confounding by comparing sexual minority youth to their heterosexual same sex twin siblings in another Swedish study. Adding general victimization in the model had limited impact on the association.

Conclusions Overall, there has been consistent evidence from many adolescent and young adult populations from several countries suggesting that discrimination and victimization variables mediate the relation between sexual orientation and depression. However, there has also been some evidence that adjusting for confounder variables such as familial confounding reduces the mediated effects.

\section{Physical or Sexual Violence}

Physical and sexual violence and abuse were investigated in some studies using assessments that did not specify whether participants thought that these experiences were due to their sexual orientation. Dating violence was found to be a mediator in the relation between sexual orientation and depression in a sample of Chinese university students. History of abuse was found to be a significant mediator in a sample of Australian women. An aggregate adversity measure that included physical and sexual abuse in childhood, housing adversity, and intimate partner violence mediated the relation between sexual orientation and various mental health outcomes including depression in an U.S. youth sample. In a female adult sample, sexual and physical abuse and parental neglect prior to age 18 were found to mediate the association between sexual minority status and depressive symptoms only when comparing heterosexual to bisexual women; no depression differences were found between heterosexual and lesbian women. Similarly, another study found history of sexual trauma was one of the factors mediating the association between bisexual identity and depression, while gay and lesbian identities did not predict depression.

One included study reported some conflicting findings. Lesbian or bisexual identities were not significant predictors 
Table 4 Statistical analysis and findings

\begin{tabular}{ll}
\hline Study & Statistical analysis \\
\hline 1. Almeida et al. (2009) & Series of regressions \\
Sobel test
\end{tabular}

2. Burns et al. (2016)

Series of regressions

3. Burton et al. (2013)

4. Donahue et al. (2017)

5. Frisell et al. (2009)

6. Frost and LeBlanc (2014)

7. Hatzenbuehler et al. (2008)

8. Hatzenbuehler et al. (2012)

9. Hughes et al. (2014)

10. Krueger et al. (2018)
Series of regressions Product of coefficients: bootstrapping

Series of regressions

Series of regressions

Series of regressions Bootstrapping

SEM

Sobel test

Series of regressions

Series of regressions

SEM

Unspecified test of significance
Findings $^{\mathrm{a}}$

Perceived discrimination mediated the relation between sexual minority status and depressive symptoms. The mediation was especially pronounced for boys

A bisexual but not a homosexual orientation was found to predict increased rates of depression compared to those with a heterosexual orientation. This association was no longer significant when other significant predictors were included in the model, including social support, physical health, smoking status, and history of sexual trauma, suggesting the potential mediating role of these variables (although the authors did not describe these as mediators)

Sexual minority-specific victimization mediated the effect of reported sexual minority status and depressive symptoms, controlling for baseline depressive symptoms and demographic variables

Results suggested that victimization attenuated the relation between sexual minority status and depression. This possible mediation effect was decreased when controlling for unmeasured familial confounding by comparing sexual minority youth to their heterosexual same sex twin siblings

Adjusting for perceived discrimination and hate crime victimization reduced the relation between same-sex sexual experience and depressive symptoms, suggesting evidence for mediation (although the authors did not describe the variables as mediators). When controlling for familial confounding with the use of within-twin-pair comparisons, men with samesex contact and those without did not differ in depression rates. For women, a significant difference based on same-sex contact remained, which disappeared when accounting for perceived discrimination and hate crime victimization

Controlling for demographic variables, greater nonevent stress (i.e., barriers to life pursuits in relationships and work) mediated the relation between sexual orientation and depression symptoms

Greater rumination and poorer emotional awareness mediated the association between same-sex attraction and depressive symptoms, while controlling for baseline levels of depression

Controlling for demographic factors, violence, and victimization, sexual minority status was no longer significantly associated with depression in boys when social isolation was included in the model. No mediation hypotheses were tested for girls, as social network variables were not found to be associated with depression in girls

Controlling for demographic variables and parental drinking, no differences in depression were found between heterosexual and lesbian women. However, bisexual women were found to have increased rates of depression compared to heterosexual women. After adjusting for the number of types of victimization, the difference in depression between bisexual and heterosexual women was no longer statistically significant

Perceived stress mediated the association between sexual minority status and depressive symptoms for all sexual minority groups of women when compared to heterosexuals. However, perceived stress was only related to sexual minority status for mostly heterosexual men and not gay/bisexual or discordant heterosexual men when compared to heterosexuals 
Table 4 (continued)

\begin{tabular}{ll}
\hline Study & Statistical analysis \\
\hline 11. la Roi et al. (2016) & SEM: latent growth modeling
\end{tabular}
Product of coefficients

12. Luk et al. (2018)

13. Luk et al. (2019)

14. Martin-Storey and August (2016)

15. Martin-Storey and Crosnoe (2012)

16. McLaren (2008)

17. McLaren et al. (2007)

18. McLaughlin et al. (2012)

19. McNair et al. (2005)

20. Mereish et al. (2019)
SEM

Bootstrapping

SEM

Delta method

SEM: latent growth modeling Bootstrapping

\section{SEM}

Bootstrapping

Series of regressions

Series of regressions

Series of regressions

Sobel test

Series of regressions
Findings $^{\mathrm{a}}$

Disparities in depression between sexual minority girls and youth of bisexual identity, present since age 11, were mediated by both victimization and parental rejection. Depression differences in boys were not found. However, peer victimization but not parental rejection mediated the association between sexual minority status and depressive symptoms for boys too. Both peer victimization and parental rejection mediated the association between bisexual identity and depressive symptoms

Family satisfaction, cyberbullying victimization, and unmet medical needs all mediated the relation between sexual minority status and depressive symptoms. Peer support was not found to mediate the association as it was not associated with sexual minority status

Controlling for ethnicity and family affluence, bisexual attraction in adolescence was both directly and indirectly associated with higher depressive symptoms during young adulthood through increased time spent on cyber behaviors (weekday and weekend) and social media. These mediation associations were not found when comparing to gay/lesbian and questioning groups to heterosexuals as these groups did not differ in cyber behaviors and social media use compared to heterosexual youth. Bisexual and questioning females reported higher depressive symptoms than heterosexual females, but such disparities were not found when comparing lesbian youth to heterosexual, or among sexual orientation subgroups in males

Controlling for socioeconomic status and method of recruitment, the relation between sexual orientation and depressive symptoms was mediated by harassment due to gender nonconformity

Controlling for demographic variables, baseline depression, and maternal depression, harassment due to sexual minority status mediated the association between sexual minority status and depression. Harassment due to sexual minority status was associated with depression via lowered sense of self-concept and negative perceptions of the school environment

Controlling for demographic variables, results provide some evidence for mediation of lower sense of belonging in the relations between of sexual orientation and dysphoria in women

Controlling for demographic variables, results provide some evidence for mediation of lower sense of belonging in the association between sexual orientation and dysphoria in men

Controlling for demographic variables, exposure to early life adversity was a significant mediator of the association between gay and lesbian orientation and depression

Controlling for demographic variables, results suggested that for the younger cohort, all sexual minority women (mainly heterosexual, bisexual, and exclusively/mainly homosexual) had higher rates of depression than heterosexual women and that stress, abuse, and lower social support attenuated these associations. For the older cohort of women, only the mainly heterosexual group had higher depression rates compared to the heterosexual group, and this difference disappeared when stress, abuse, and lower social support were added to the model

Controlling for demographic variables, cyber and bias-based victimization mediated the relation between sexual orientation and depression outcomes in Black American young people 
Table 4 (continued)

\begin{tabular}{lll}
\hline Study & Statistical analysis & Findings $^{\mathrm{a}}$ \\
\hline 21. Miller and Irvin (2016) & $\begin{array}{l}\text { Series of regressions } \\
\text { Sobel test }\end{array}$ & $\begin{array}{l}\text { Controlling for demographic variables, lower emotional sup- } \\
\text { port mediated the relation between sexual orientation and } \\
\text { depression for victims of intimate partner violence. The type } \\
\text { of abuse experienced (verbal, physical, and sexual) did not } \\
\text { mediate the relation }\end{array}$
\end{tabular}

22. Needham and Austin (2010) Series of regressions

Bisexual women but not lesbian women had elevated depressive symptoms compared to heterosexual women. Controlling for demographic variables, results were consistent with the suggestion that the association between bisexual identity and depressive symptoms was attenuated when parental support was included in the model. Gay and bisexual men were not found to differ to heterosexual men in depression rates

23. Oginni et al. (2018)

24. Pakula et al. (2016)

25. Pearson and Wilkinson (2013)

26. Przedworski et al. (2015)

27. Riley et al. (2016)

28. Robinson et al. (2013)

29. Rosario et al. (2014)

30. Safren and Heimberg (1999)

Series of regressions

SEM

Unspecified test of significance

Series of regressions

Series of regressions Product of coefficients: bootstrapping

Series of regressions Sobel test

Series of regressions

Series of regressions Bootstrapping

The family-related variables examined resulted in an attenuation in the relation between sexual orientation and depressive symptoms, but this attenuation was not significant. Entering resilience in the model resulted in a significant attenuation in the relations between sexual orientation and depressive symptoms, suggesting the mediating role of resilience (although the authors did not describe it as a mediator)

After controlling for demographic variables, greater life stress significantly mediated the associations between sexual identity and mood disorders for both gay/lesbian and bisexual respondents

For girls, perceived closeness with parents and family support mediated the association between same-sex attraction and depressive symptoms. For boys, perceived parental closeness mediated the association of same-sex attraction and depressive symptoms. Results suggested that poorer family relationships were a stronger mediator for girls than for boys

After controlling for demographic variables, results suggested that social stressors decreased the magnitude of the association between sexual minority status and depression

After controlling for demographic and baseline levels of depression, stress and coping styles (denial, blame, reframing and religion) were not found to mediate the association between sexual identity and depression

In both girls and boys, peer victimization mediated the disparities in indicators of depressive distress

After controlling for demographic variables and sibling clustering, less secure maternal attachment attenuated the relation between sexual orientation and depressive symptoms for bisexual and mostly heterosexual youth compared to heterosexual youth. For lesbian and gay youth, the association disappeared once attachment was entered in the model. There was no evidence that maternal affection mediated depression disparities between the sexual minority subgroups and heterosexuals

Sexual minority status was related to potential mediators (although the authors did not describe these as mediators) stress and social support, but not acceptance coping. Sexual minority status was related to depression in a univariate model, but this was no longer the case when the stress, social support, and acceptance coping variables were added into the model

Heterosexual women survivors of sexual assault had lower depressive symptoms than bisexual women survivors. Lower perceived social support mediated the association between sexual orientation and depressive symptoms 
Table 4 (continued)

\begin{tabular}{ll}
\hline Study & Statistical analysis \\
\hline
\end{tabular}

32. Smith et al. (2016)

33. Spencer and Patrick (2009)

Series of regressions

34. Shenkman et al. (2019)

35. Szalacha et al. (2017)

36. Tate and Patterson (2019)

37. Teasdale and Bradley-Engen (2010) Series of regressions

38. Ueno (2010)

Series of regressions

39. Wong et al. (2017)

40. Woodford et al. (2014)
SEM

Bootstrapping

SEM

Bootstrapping and Sobel test

Series of regressions Bootstrapping

Series of regressions

Series of regressionsBootstrapping
Findings $^{\mathrm{a}}$

Results suggested that greater self-reported institutional betrayal attenuated the relation between sexual minority status and depression

The association between sexual orientation and depressive symptoms disappeared when personal resources of social support and mastery were entered into the model. Both social support and personal mastery uniquely contributed to depression variance

Controlling for demographic variables, attachment avoidance mediated the association between being gay or lesbian and depressive symptoms

Having a lesbian or bisexual sexual identity was not found to predict depression, while a mainly heterosexual sexual identity was. Despite the number of types of interpersonal violence emerging as the strongest predictor of depression in the model, no evidence for mediation was found

Controlling for sociodemographic variables, higher perceived stress and lower relationship quality with fathers mediated the relation between lesbian, gay, and bisexual identities and depressive symptoms. Lower relationship quality with mothers and higher perceived stress mediated the relation between sexual minority status and depressive symptoms in women but not in men. For men, there was no difference in relationship quality with mothers among sexual orientation groups

Controlling for demographic variables, results suggested that greater social stress (including victimization, witness victimization, forced sexual encounters, and suicide of a friend) and lower social support (perceived care and social acceptance by peers, parents, and teachers) attenuated the relation between sexual minority status and depressive outcomes

Victimization and daily discrimination attenuated the relation between same-sex contact and depressive symptoms. Negative life events and chronic strain also attenuated the association independently. Similarly, family relationships decreased the association, as well as psychological resources (mastery, self-esteem, and mattering). When all the hypothesized mediators were simultaneously entered in the model the difference between those with same-sex contact and those without was greatly reduced but was still significant. There was no evidence that self-exploratory attitudes (fun-seeking orientation, number of sexual partners, and early sexual initiation) explained the association between same-sex contact and depressive symptoms. The variables of major discrimination, friend support, relationship status, and optimism were not tested for mediation as there were no differences between the groups on these factors

After controlling for demographic variables and adverse childhood experiences, dating violence and sexual orientation concealment both independently mediated the relation between sexual minority status and depressive outcomes

After controlling for demographic variables, more experiences of interpersonal mistreatment (incivility and heterosexist harassment) mediated the relation between sexual minority status and depression

aTerms such as "boys," "girls," "men," and "women" are used to report the findings of studies in line with the terms used in the papers; generally, the authors did not report how they assessed sex/gender/gender identity 
of depression, but identifying as mainly heterosexual was significantly associated with depression. Mainly heterosexual women still reported higher rates of depression than heterosexual women after controlling for interpersonal violence, suggesting that there was not sufficient evidence of interpersonal violence as a mediator, despite interpersonal violence being a predictor of depression in the model.

Conclusions Physical and sexual abuse was found to mediate the relationship between sexual orientation and depressive outcomes in most studies that tested such variables, particularly for individuals with a bisexual identity.

\section{Stress-related Factors}

Studies reported positive findings when using a range of stressrelated measures including perceived stress, a low number of positive events, social stress measures, negative life events and nonevent stress, in the form of barriers to core life pursuits. On the other hand, stress did not meet the criteria for mediation in a sample of university students once baseline depression was controlled for. In another study, perceived stress mediated the relation between sexual orientation and depressive symptoms when lesbian and bisexual women, mostly heterosexual women, discordant heterosexual women (i.e., women who identified as heterosexual but reported same-sex attractions and/or behaviors), and mostly heterosexual men were compared to concordant heterosexual men (i.e., men who identified as heterosexual and whose reported attractions and behaviors were all toward the opposite sex). However, this association was not found for gay, bisexual, or discordant heterosexual men, as these categories did not report more perceived stress than their heterosexual counterparts.

Unmet medical needs was found to be a significant mediating factor in the relation between sexual orientation and depression in a US youth sample. Physical health and healthrelated behaviors like smoking contributed to the relation between bisexual identity and depression, in a study that found depression disparities between heterosexuals and bisexuals but not between lesbian/gay and heterosexuals. Another included study found that time spent on cyber behaviors and social media was a significant mediator between bisexual attraction and depression outcomes, while such associations were not found when comparing gay and lesbian to heterosexual groups.

Conclusions Many studies suggested that different types of perceived stress were mediators, whilst a minority of studies showed some contradictory findings. Physical health disparities, unmet medical needs, and social media factors were also found to be mediators.

\section{Family Relationships and Social Support}

Studies investigating attachment and family-related factors had mainly positive findings with some evidence for sex and sexual orientation subtype differences. Cross-sectional samples of adolescents and young adults found secure attachment and family support, respectively, to attenuate the relation between sexual orientation and depression symptoms. However, conflicting evidence was found for attachment avoidance, which mediated the association between sexual minority status and depressive outcomes in an adult Israeli sample but was not supported as a mediator in a longitudinal adolescent sample. A study found some evidence of mediation for parental support but only when comparing bisexual to heterosexual women, as other groups were not found to differ in depression rates.

Gender or sex differences were found in several longitudinal studies. For example, parental rejection was found to be a significant mediator for girls but not for boys in a large longitudinal study. Similarly, another research study found that for girls, perceived closeness with parents, parental involvement, and perceived family support was a significant mediator, with perceived family support being the most important factor. For boys, family relationship variables seemed to explain less of the association than for girls, but closeness with parents was a significant mediator.

The relationships with mothers and fathers were also found to have a differentiating role in one of the studies: whereas lower relationship quality with fathers was a significant mediator in both men and women, lower relationship quality with mothers mediated that association only in women. On the other hand, reported family satisfaction mediated the relation between sexual orientation and later depression equally for girls and boys in one of the other included studies.

Evidence of mediation using general social support measures was reported in studies of adolescents, in women who had experienced intimate partner violence, and in bisexual versus heterosexual women who were survivors of sexual assault. Moreover, two other studies found that social support, along with other mediators, attenuated the relation between sexual minority identity and depressive symptoms and a third demonstrated the same finding but only for those with a bisexual identity. Social isolation was found to mediate the relation between same-sex attraction and depression in males but this was not found in females.

More systemic measures of social support were also found to be significant mediators: a sense of belonging in the community, negative perceptions of school environment, and institutional betrayal relating to sexual assault in undergraduate students.

Conclusions Studies generally indicate that sexual minority individuals experience to a lesser degree the protective effects of social support and other systemic factors (e.g., quality of the environment or a sense of belonging) and that these may help explain increased depression rates. Parental relationships and support may partly explain depression disparities, with some studies suggesting that this mechanism 
may be stronger for girls than boys. Internalized relationship representations and attachment styles may also play a role.

\section{Intrapersonal Factors}

A wide range of different intrapersonal psychological processes were investigated as potential mediators, with stronger evidence for self-esteem than for specific coping mechanisms. There was evidence from a few studies that self-concept, self-esteem, personal mastering, and a sense of mattering were significant mediators. Another study found evidence for mediation of a resilience measure that included items related to optimism and mastery. Lower emotional awareness and greater rumination were found to be significant mediators, but some of the studies did not find enough good evidence for other response styles, such as acceptance coping, denial, and blame.

Self-exploratory attitudes, including fun-seeking, number of sexual partners, and age of first sexual experience, did not account for the association between same-sex contact and symptoms of depression in a young adult sample. One study investigated sexual orientation concealment and found it to be a significant mediator in a sample of Chinese university students.

Conclusions Support for a range of intrapersonal psychological factors was reported, but each of these tended to be investigated in single studies and therefore require replication.

\section{Discussion}

The aim of the present study was to review research evidence regarding psychosocial factors that may mediate the increased depression rates in sexual minority compared to heterosexual populations. Forty studies were identified and reviewed, examining as mediators constructs related to discrimination, victimization, violence, stress, social support and other interpersonal factors, as well as intrapersonal psychological processes.

It is perhaps unsurprising that such a diverse set of psychosocial factors have been proposed to explain the complex phenomenon of increased depression rates in sexual minorities compared to heterosexuals. The breadth of mediators suggested by existing evidence indicates that identifying the most important mediators is probably less crucial than recognizing the multitude of stressors that sexual minority individuals continue to face, and the different effects that such stressors have on individual psychological resources and coping mechanisms that make them either more vulnerable or resilient. Theoretical frameworks such as the minority stress model (Meyer, 2003) and the psychological mediation framework (Hatzenbuehler, 2009) help conceptualize the synergic effect of mediators and demonstrate the necessity of multiple and coordinated responses at different levels of the system. The implications for theory and intervention are further discussed in the next section.

It is worth noting that three of the studies reviewed controlled for familial confounding when examining victimization and maternal attachment as mediators. Two of these studies found that the mediation relations were weaker or disappeared when comparing among twin siblings. This led the researchers to suggest that shared genetic or environmental influences may play an important role in explaining depression disparities, without ruling out the possibility that minority stressors affecting heterosexual siblings may help explain their findings. In contrast, the third study found that attachment was still a mediator after controlling for sibling clustering. These findings along with other research (Zietsch et al., 2011) investigating shared etiological factors indicate that it is possible that genetic and/or environmental familial factors not directly related to sexual minority identification contribute to increased depressive symptoms in sexual minority individuals. It has also been argued that minority stressors and stigma may affect the heterosexual twins and other members of the family (Donahue et al., 2017; Timmins et al., 2018) which may help explain these findings.

\section{Implications}

The vast majority of the studies demonstrate further evidence of increased prevalence of depressive symptomatology in sexual minorities in a diverse range of samples and age groups. This illustrates that sexual minorities continue to represent an at-risk population, reaffirming the importance of developing a comprehensive understanding of psychosocial processes that represent vulnerability factors. Such factors offer specific targets for preventative and therapeutic efforts.

The findings of this review are largely consistent with minority stress theory, according to which disproportionate stress related to stigma and discrimination results in elevated rates of psychological distress (Meyer, 2003). Most studies in this review report evidence that supports the suggestion that sexual minority individuals experience more stressors including harassment, victimization, violence, abuse, parental rejection, and other forms of adversity, and receive less social support and access to valued positive experiences than their heterosexual counterparts.

The review illustrates that there has been a greater emphasis in the literature on minority stressors than on the general interpersonal, emotional regulation, and cognitive processes through which such stressors increase people's risk for depression (Hatzenbuehler, 2009). While understanding minority stressors is an important endeavor that can help address their impact on a broader sociopolitical and community level, a more careful exploration of these subsequent 
processes can provide targets for psychological interventions on an individual level. Where such factors were investigated, findings were consistent with Hatzenbuehler's psychological mediation framework. Studies reviewed here reported low social support, increased rumination, low emotional regulation, poor sense of mastery, low resilience, and low self-esteem as factors that can help explain the increased rates of depression in sexual minority individuals. The literature could be expanded further to test all four components of Hatzenbuehler's mediation paradigm. This can be achieved by using, for instance, serial mediation pathways to demonstrate how sexual minority orientation leads to increased exposure to stressors, which in turn lead to increased levels of individual psychological processes, which then contribute to elevated rates of depression. It is also important to gain a much better understanding of how different types of stressors may mediate depression risk via particular intermediate emotional/interpersonal/cognitive processes. Such specific pathways are not specified in Hatzenbuehler's framework. An example would be to explore how experiences of family rejection based on sexual orientation lead to more negative beliefs about others and oneself that then put individuals at risk for depression.

These general psychological processes should be explored in parallel to group-specific proximal stressors such as internalized stigma, rejection sensitivity, and concealment that are also known to confer vulnerability for sexual minorities. For instance, the literature has suggested that dealing with issues of concealment is associated with maladaptive cognitive, affective, and behavioral strategies that are related to adverse mental health outcomes (Leleux-Labarge et al., 2015; Pachankis, 2007).

Policy makers, clinicians, families, schools, universities, and communities all have a role to play in addressing or mitigating the impact of stigma-related stressors for sexual minorities. Community, school, or university interventions that aim to target victimization, increase social support and benevolent experiences, and enhance positive identity development and a sense of belonging are likely to be protective. Moreover, evidence on parental and family support highlights the need for development of interventions that facilitate awareness, education, support, and normalization for parents and families, as well as access to support for youth who face family rejection or alienation due to concealed or disclosed identities.

Existing evidence about the cognitive and regulatory mechanisms that have been shown to be intermediate factors, both group-specific stressors such as internalized stigma and general processes such as lower self-esteem and rumination, can also inform the development of therapeutic interventions. Addressing such psychological processes is a key component of cognitive behavior therapy (CBT) for depression. There is emerging literature on CBT interventions adapted for sexual minority populations (e.g., Craig \& Austin, 2016; Craig et al., 2012; Lucassen et al., 2015; Pachankis et al., 2015). Psychological interventions can also test psychological mediators as mechanisms of change in randomized-controlled trials (RCTs) for sexual minority individuals with mood difficulties. Change in both minority-specific and general potential mechanisms were investigated in an RCT that targeted minority-stress-focused processes in a transdiagnostic CBT treatment for sexual minority women experiencing depression, anxiety, and heavy alcohol use (Pachankis et al., 2020). The study provided evidence supporting the efficacy of the treatment in reducing participants' depression and anxiety. They found no condition by time interactions for the minority stress processes (rejection sensitivity, concealment, internalized stigma) or general processes (emotional regulation difficulties, rumination, and assertiveness) with the exception of social support which showed results in the opposite direction to expected. However, in pooled analyses, they found small-to-medium pre-post-reductions for the general processes with small effects for the minority stress processes. Future minority-specific interventions may consider addressing other processes such as those arising from the increased levels of violence and abuse experienced by sexual minority individuals (Roberts et al., 2010). Finally, although more research is needed, mental health practitioners can use this review as a guide of the multitude of vulnerability factors that can be considered in case formulations and interventions with sexual minority clients presenting with depression.

\section{Limitations of Studies}

The methodological quality of studies varied, with just under a fifth of the studies suffering from important methodological limitations. Many studies had significant response and attrition issues. Furthermore, only one study used diagnostic interview questions to assess the presence or absence of clinical depression, rather than relying on self-report measures of depressive symptoms or the presence of a depression diagnosis. While self-report questionnaires can indicate high levels of depressive symptoms, they should not be used on their own to diagnose depression. Psychiatric diagnosis requires that the individual has a minimum number of a set of symptoms, experiences them at a specified frequency, suffers significant impairment in at least one life domain as a result of the symptoms, and that other possible causes of the symptoms have been excluded. In addition, many studies used measures for their mediators for which there was inadequate evidence of validity and/or reliability.

Another serious methodological issue was that the majority of the reviewed studies were cross sectional. A crosssectional design does not allow the examination of causal pathways and therefore conclusions cannot be drawn about the predictive value of the independent variable and the 
mediators. For example, one might argue for reverse causality, arguing that, for instance, depression may lead to isolation and decreased social support. Furthermore, many studies used retrospective self-reports to assess mediators such as victimization, abuse, and social support. When retrospective self-reports are used, recall biases may inflate the associations demonstrated. This is especially the case if mediation measures are collected at the same time with measures of depression, as the mood-congruent memory bias observed in depression (e.g., Watkins et al., 1996) could affect the way individuals report their past experiences.

Another complication related to temporality was that a few cross-sectional studies used history of experiences such as victimization without specifying a specific time frame. Such experiences might have therefore occurred before participants identified as sexual minority (e.g., in childhood). This violates mediation theory in that the independent variable would not necessarily precede the mediator in time. It is hence debatable whether these studies can claim that they provide evidence for mediation.

While some of the studies measured variables of interest in a longitudinal fashion, none of them used data from several different waves of measurement; they either measured sexual orientation and mediator at time 1 and depression at time 2 , or sexual orientation at time 1 and mediator and depression at time 2. In addition, some of the longitudinal studies did not control for baseline depression levels and none of the studies controlled for baseline measures of the mediator. Controlling for baseline scores is important as it generally explains a great deal of the variance in later measures, thus improving precision and power to detect effects of the mediator on the outcome.

Many studies had significant limitations in the statistical approaches they used to examine mediation. Many used the causal steps approach (Baron \& Kenny, 1986) without then calculating an indirect/mediated effect or conducting a statistical test for this effect. The limitations of using the causal steps approach without examining the mediated effect have been well documented in mediation analysis literature (e.g., MacKinnon et al., 2002). Whereas it is important to demonstrate that sexual minority status is related to mediators (a path) and mediators are related to depressive outcomes (b path), if one is conducting mediation analysis the magnitude of the mediated effect is also of interest, which can only be examined if an indirect effect is calculated and evaluated with a test of significance. Moreover, many studies did not report exactly which statistical tests they used. Others failed to follow good practices in reporting mediation analysis results, such as reporting which tests they used for testing the significance of the indirect effect, or presenting confidence intervals of direct and indirect paths. In addition, although many studies had large samples, very few studies provided a justification for sample size selected or reported a power analysis.
One study did not report estimates for individual mediators which makes interpretations about their unique contribution very difficult. Finally, the lack of reported effect sizes by many studies and the diverse statistical methodologies used precludes us from being able to usefully comment on or compare between mediation effect sizes in different studies. Even when studies used the same constructs as mediators (e.g., victimization), they operationalized and assessed them in different ways. Therefore, drawing conclusions about the comparative strength or importance of mediators between studies would be misleading. It would be useful to have a unified method for reporting mediation studies so that effect sizes could be extracted and meta-mediation analyses could be conducted.

A significant minority of the studies used large cohort samples which are generally more representative of the population they wish to test. However, many of the studies used subsamples of the population or convenience samples. For example, the wide use of university samples by the studies, while common in psychology research, has been argued to be problematic as university students tend to have higher socioeconomic status and are largely homogenous (Hanel \& Vione, 2016). Moreover, over a fourth of the studies included in this review used the same or overlapping samples, albeit using different designs and time points and testing different mediators.

There was considerable variability in how sexual minority status was defined and categorized, as well as to how depression was measured, which limits the ability to directly compare results across different studies in reviews and metaanalyses. An ongoing issue in sexual minority research is the operationalization and measurement of sexual minority status. Definitions can be based on identity, behavior, attraction, and/or preference for romantic partners; a few studies use combinations of these factors. Future research should use multiple indicators and investigate, for example, whether the implications of self-labeling as a sexual minority, and therefore associating oneself with a stigmatized identity, are different in relation to depression than same-sex behaviors in the absence of such an identity.

Furthermore, most studies did not investigate differences across sexual minority subgroups due to issues with sample size and power, with some of the studies ignoring or excluding some groups from their analysis. Further research can aim to develop a better understanding of the distinct issues and outcomes that different sexual minority groups face. For example, there is some evidence to suggest that bisexuals may have especially high risk for mental health problems (Burns et al., 2016; Hughes et al., 2014; Luk et al., 2019; Needham \& Austin, 2010). Groups identifying as mostly heterosexual are also poorly understood with some research included in this review reporting similar or worse outcomes 
for them compared to other sexual minority groups (Corliss et al., 2009).

In this review, terms such as "boys," "girls," "men," and "women" are used to report the findings of studies in line with the terms used in the papers; generally, the authors did not report how they assessed sex or gender. In most studies, gender identity was not assessed or discussed, and the distinctions between sex, gender, and gender identity were not taken into account. Future studies should explore the gender identity of participants and report how their gender or sex was assessed.

The overwhelming majority of studies reviewed took place in specific locations within the U.S. Research findings will be affected by the policy and societal climate of the time and place in which the studies were conducted. Sexual minority stressors are likely to vary significantly across countries as well as within countries in different sections of the population. As research continues to take place in other locations, it will be important to compare the factors mediating depression risk for sexual minorities across different social contexts.

\section{Limitations of the Review Process}

This review did not include grey literature and research that was not published in peer-reviewed journals. As a consequence, it is possible that the well-documented bias of reporting and publishing mostly positive results in scientific journals can affect the conclusions. Although this review did present a few negative findings, it is still likely that a publication bias conceals research findings about factors that do not mediate the differing depression rates among sexual minority and heterosexual individuals. Moreover, this review did not include research that was not published in languages other than English which may have restricted the inclusion of studies that took place in different parts of the world. Lastly, as aforementioned, the heterogeneity in methodological approaches among studies, including the use of different operational definitions of sexual minority orientation and depression, undermines comparisons and synthesis of findings between studies. The overview of the findings in the Results section is open to authors' biases but readers can find much more detailed information in the tables and the Appendix.

\section{Conclusions and Directions for Future Research}

This review found evidence consistent with suggestions that stressors such as victimization, harassment, abuse, life stress, and reduced social and familial support contribute to the increased depression rates found in sexual minority individuals compared to heterosexuals. There was also some evidence suggesting that differences in psychological processes such as self-esteem, mastery, emotion regulation, rumination, and coping styles may also play a role. Such understanding is important in directing wider sociopolitical factors and policy issues that can help address mental health inequalities, as well as informing community and clinical interventions.

However, the methodological limitations of the studies mean that no firm conclusions should be drawn and higher quality research is needed. Prospective studies are required in which sexual orientation, mediators, and depression outcomes are assessed at three consecutive time points. Furthermore, appropriate statistical methods should be used to examine mediation processes. Studies using longitudinal designs with at least three time points to test mediators of sexual minority status and depression would allow researchers to draw firmer conclusions about which mediators should be the target of interventions. Randomized research designs could then be used in which at-risk individuals are offered interventions aimed at addressing a hypothesized mediator, such as self-esteem or social support. Proper estimation of mediated effects in intervention studies would provide the best test about the impact of hypothesized mediators in the depressive symptomatology of sexual minority individuals by assessing whether the intervention targeted the mediator of interest and whether the mediator of interest had in turn an effect on depressive outcomes. Studies using structured assessment of clinical depression are required to overcome some of the limitations associated with self-report of depressive symptomatology.

Since this review was conducted, we have published a study that addressed many of these methodological issues outlined here, by assessing variables at three separate timepoints, controlling for baseline depression, and using robust statistical methodology in a large longitudinal sample of UK youth. The study found evidence of poorer family relationships and unhelpful assumptions as mediators as well as weaker support for self-esteem as a mediator (Argyriou et al., 2020).

Further research is needed to better understand possible psychological mechanisms through which minority stressors exert their impact on mental health. Research could also explore whether and how shared genetic or environmental factors relate to the elevated depression risk of sexual minorities, independently from minority stressors. Different aspects of sexuality such as attraction, identity, and behavior should be studied in order to better understand their association with different risk factors and outcomes. Some studies in this review reported distinct findings for males and females, but more research into differences in relation to sex and gender identity is required. Greater use of general population samples rather than convenience samples would help overcome potential issues of participation bias. However, where specific subgroups have been underrepresented (e.g., bisexual or mostly heterosexual individuals), targeted recruitment methods may be required. Finally, further research is 
needed from other countries and cultures and across sexual minority subgroups, including bisexual and mostly heterosexual individuals, as processes may vary between individuals experiencing different types of minority stressors.

Acknowledgement The authors wish to thank Dr. Susanne Meisel who was the second rater of the methodological quality assessment and Dr. Alkeos Tsokos who assisted with proof-reading.

Funding This paper represents independent research part funded by the National Institute for Health Research (NIHR) Biomedical Research Centre at South London and Maudsley National Health Service Foundation Trust and King's College London. The UK National Health Service, the NIHR, and the UK Department of Health and Social Care had no role in the study design, collection, analysis, or interpretation of the data, writing the manuscript, or the decision to submit the paper for publication.

\section{Compliance with Ethical Standards}

Conflict of interest There are no conflict of interest to declare.

Open Access This article is licensed under a Creative Commons Attribution 4.0 International License, which permits use, sharing, adaptation, distribution and reproduction in any medium or format, as long as you give appropriate credit to the original author(s) and the source, provide a link to the Creative Commons licence, and indicate if changes were made. The images or other third party material in this article are included in the article's Creative Commons licence, unless indicated otherwise in a credit line to the material. If material is not included in the article's Creative Commons licence and your intended use is not permitted by statutory regulation or exceeds the permitted use, you will need to obtain permission directly from the copyright holder. To view a copy of this licence, visit http://creativecommons.org/licenses/by/4.0/.

\section{Appendix}

\begin{tabular}{ll}
\hline Study & Sample characteristics \\
\hline 1. Almeida et al. (2009) & Age: $13-19$ years $(M=16.3, S D=1.3)$ \\
& Gender: $58.3 \%$ females, $41.7 \%$ males \\
& Ethnicity: $30.7 \%$ Hispanic, $44.8 \%$ non- \\
& Hispanic Black, $10.8 \%$ Asian/Pacific \\
& Islander/biracial/multiracial/other \\
2. Burns et al. (2016) & Age: $48.5 \%$ of the sample were between \\
& 20 and 24 years, 51.5\% of the sample \\
& were $40-44$ years \\
& Gender: $47.9 \%$ females, $52.1 \%$ males
\end{tabular}

3. Burton et al. (2013)

Age: $14-19$ years $(M=17, S D=1.36)$

Gender: $70 \%$ females, $20 \%$ males

Ethnicity: 31\% White, 63\% AfricanAmerican, $3 \%$ other

4. Donahue et al. (2017) Age: 18 years

Gender: $59.3 \%$ females, $40.7 \%$ males

5. Frisell et al. (2009)
Age: 20 to 47 years $(M=33.7)$

Gender: $39.8 \%$ females, 60.2 males

Education: $4.4 \%$ low, $47.3 \%$ medium,

45.7\% high, $2.6 \%$ missing

Currently in relationship: $73.5 \%$ yes, $25.3 \%$ no, $1.2 \%$ missing
Measures for mediator(s)

Perceived discrimination: single yes/no item

Major life events: Age first moved away from the parental home; age first moved in with first partner; age of first sex; measure of traumatic life events

Social support: Estimated from a factor analysis of the Schuster Social Support Scale (Schuster, Kessler, \& Aseltine, 1990) assessing family, partner, and friend negative/positive support

Health and behaviors: Continuous Short Form-12 Physical Health Component Score that was computed following the RAND scoring (Hays, Sherbourne, \& Mazel, 1993), and a binary indicator for Self-Rated Health

Behavioral activation and inhibition: $B I S-B A S$, a measure of behavioral activation and inhibition (Carver \& White, 1994)

Sexual-minority specific victimization: Victimization due to actual or perceived sexual minority status assessed via four items

Victimization: Dichotomous variable based on reports of experiencing emotional abuse, physical abuse/neglect, sexual abuse/assault

Perceived victimization: Self-report of ever having been "discriminated against in an insulting or disparaging way."

Hate crime victimization: Single item asking whether respondents have experienced violence due to their "race, ethnicity, gender, sexual orientation, or religion" 


\begin{tabular}{|c|c|}
\hline Study & Sample characteristics \\
\hline $\begin{array}{l}\text { 6. Frost and LeBlanc } \\
\text { (2014) }\end{array}$ & $\begin{array}{l}\text { Age: } M=31.71 \text { years }(S D=10.75) \\
\text { Gender: } 69.4 \% \text { females, } 30.6 \% \text { males } \\
\text { Ethnicity: } 71 \% \text { White, } 14 \% \text { Black, } 6 \% \\
\text { Latino, } 6 \% \text { Asian, } 2 \% \text { Native American, } \\
1 \% \text { Pacific Islander, } 7 \% \text { other } \\
\text { Education: } 57 \% \text { some college or more, } \\
43 \% \text { high school diploma or less } \\
\text { Employment: } 52 \text { full-time, } 20 \text { part-time, } \\
14 \text { unemployed, } 36 \text { student } \\
\text { Relationship status: } 43 \% \text { single, } 57 \% \text { in a } \\
\text { relationship }\end{array}$ \\
\hline $\begin{array}{l}\text { 7. Hatzenbuehler et al. } \\
\text { (2008) }\end{array}$ & $\begin{array}{l}\text { Age: } 11-14 \text { years } \\
\text { Grades: } 31.8 \% \text { in sixth grade, } 33.9 \% \text { in } \\
\text { seventh grade, } 34.3 \% \text { in eighth grade } \\
\text { Gender: } 48.8 \% \text { females, } 51.2 \% \text { males } \\
\text { Ethnicity: } 13.2 \% \text { non-Hispanic White, } \\
11.8 \% \text { non-Hispanic Black, } 56.9 \% \text { His- } \\
\text { panic, } 2.2 \% \text { Asian/Pacific Islander, } 0.2 \% \\
\text { Native American, } 0.8 \% \text { Middle Eastern, } \\
9.3 \% \text { biracial or multiracial, } 4.2 \% \text { mem- } \\
\text { bers of other racial/ethnic groups, } 1.3 \% \\
\text { unspecified racial/ethnic background } \\
\text { Household: } 27.4 \% \text { lived in single-parent } \\
\text { households }\end{array}$ \\
\hline
\end{tabular}

8. Hatzenbuehler et al. Age: $12-18$ years (Grades 7 to 12 )

(2012) Gender: $51 \%$ females, $49 \%$ males

9. Hughes et al. (2014) Age: $M=45.18$ years $(S E=1.21)$

Ethnicity: $65.3 \%$ non-Hispanic White, $20 \%$ non-Hispanic Black, $11.6 \%$ Hispanic, $3.1 \%$ other

Education: $37 \%$ high school or less, $31.9 \%$ some college, $16.8 \%$ college degree, $14.2 \%$ graduate/professional degree

Residence: $59.9 \%$ urban, $15.7 \%$ rural, $24.4 \%$ Chicago metropolitan

10. Krueger et al. (2018) Age: 24-34 years

Gender: $53.3 \%$ females, $46.7 \%$ males Ethnicity: 11.8\% Hispanic, $15.7 \%$ non-

Hispanic Black, $3.25 \%$ non-Hispanic

Asian, $69.1 \%$ non-Hispanic White

11. la Roi et al. (2016) Age: wave 1: $M=11.1$; wave $2: M=13.6$; wave $3: M=16.3$; wave $4: M=19.1$; wave $5: M=22.3$

Gender: $54.8 \%$ females, $45.2 \%$ males

12. Luk et al. (2018)

\section{Measures for mediator(s)}

Nonevent stress: assessed in the form of perceived barriers to participants' pursuit and achievement of personal projects. Barriers to project pursuit were measured with the Personal Project Inventory (PPI; Little, 1983) ( $\alpha=.58$ to .90)

Emotional regulation: emotional awareness and rumination:

Emotional awareness subscale of the Emotion Expression Scale for Children (Penza-Clyve \& Zeman, 2002) assesses extrinsic processes of emotion regulation. ( $\alpha=.88$ for full sample; $\alpha=.87$ for heterosexuals; $\alpha=.91$ for sexual minorities)

Children's Response Styles Questionnaire (CRSQ, Nolen-Hoeksema $\&$ Morrow, 1991) ( $\alpha=.86$ for full sample; $\alpha=.86$ for heterosexuals; $\alpha=.81$ for sexual minorities)

Social network variables based on peer nominations with 3 indicators: Social isolation: Two measures of social isolation were calculated: (a) in-degree (b) out-degree

Degree of connectedness: The total number of students the participant could reach in three steps in the participant's network

Social status: Bonacich's (1987) centrality measure was used to capture social status within the peer network

Victimization: A measure of cumulative victimization that summed the number of types of victimization experienced across the lifespan was created including different types of childhood abuse and adult victimization and intimate partner violence.

Perceived stress: Four-item version of the Cohen Perceived Stress Scale (Cohen, Kamarck, \& Mermelstein, 1983)

Peer victimization: Single item on bullying and three items on relational victimization $(\alpha=.85)$

Parental rejection: Self-reported parental rejection from the $E M B U-C$ (Markus, Lindhout, Boer, Hoogendijk, \& Arrindell, 2003). wave 1: $\alpha=.84$ for rejection by father; $\alpha=.84$ for rejection by mother; wave 4 : $\alpha=.70$ for rejection by father; $\alpha=.67$ for rejection by mother

Age: From 11th grade to 3 years after high Family satisfaction: Single item on self-reported satisfaction with the school, $M=17.2$ at wave 2

Gender: $56.2 \%$ females, $43.8 \%$ males

Ethnicity: 58.8\% White, 17.3 African-

American, $19.7 \%$ Hispanic, $4.3 \%$ other SES: $23.1 \%$ low, $50 \%$ middle, $27 \%$ high relationships in their families. Responses coded as low, moderate, high, or very high

Peer support: Participants nominated up to 6 of their closest male and female friends and the indicated whether they have talked with each of the friends about a problem in the last week

Cyberbullying victimization: Single item on cyberbullying

Unmet medical needs: Single yes/no item 


\begin{tabular}{ll}
\hline Study & Sample characteristics \\
\hline 13. Luk et al. (2019) & Age: wave 2: $M=17.2, S D=0.51$; wave 7: \\
& $M=22.6, S D=0.53$ \\
& Gender: $59.4 \%$ females, $40.6 \%$ males \\
Ethnicity: $58.9 \%$ White, $19.7 \%$ African- \\
American, $17.2 \%$ Hispanic, $4.3 \%$ other \\
Family affluence: $23.1 \%$ low, $49.7 \%$ \\
medium, $27.2 \%$ high
\end{tabular}

14. Martin-Storey and August (2016)

15. Martin-Storey and Crosnoe (2012)

16. McLaren (2008)
Age: non-LGB $M=20.3$ years $(S D=1.5)$, LGB $M=20.29$ years $(S D=1.4)$

Gender: $58 \%$ females, $42 \%$ males

Ethnicity: $19.5 \%$ Asian, $4.4 \%$ Black/ African-American, $61 \%$ White, $10 \%$ Hispanic, 5\% unspecified

Family-of-origin income: Incomes were distributed over the range presented, with $7.2 \%$ of the sample having families with incomes of $\$ 20,000$ yearly or less

Residence: $36 \%$ grew up in a city, $53 \%$ in a suburb, $11 \%$ in a rural area

Education: $91 \%$ attended a university, $9 \%$ attended a community college

Age: 15 years

Gender: $50.9 \%$ females, $49.1 \%$ males Ethnicity: $81 \%$ White, $12 \%$ AfricanAmerican, $1 \%$ Asian or Pacific Islander. $5 \%$ other

Family structure: $63 \%$ had father present at home

Relationship status: $55 \%$ heterosexuals $/ 57 \%$ lesbians were married or in a committed relationship

Education: $48 \%$ of heterosexual women and $29 \%$ of lesbians had completed secondary school; $25 \%$ of the heterosexual women, and $47 \%$ of the lesbians had completed a university degree
Measures for mediator(s)

Cyber behaviors: Two items (weekday, weekend time) assessed the number of hours per day participants usually use a computer, the Internet, or a cell phone for chatting online, e-mailing, texting, tweeting, or social networking. Final items ranged from 0 (none at all) to 7 (about 7 or more hours a day)

Social media use: Participants reported frequency of engagement in seven different activities on a social networking site in the past three months. Response options ranged from 0 (never) to 5 (multiple times a day) $(\alpha=.91)$

Harassment due to gender nonconformity: Frequency with which had experienced victimization events "because other people think that the way they act or dress does not match the sex they were assigned at birth, or their gender nonconformity" $(\alpha=.84)$

Harassment due to sexual minority status: Frequency with which had experienced victimization events "because of their actual sexual orientation or their perceived sexual orientation." $(\alpha=.82)$

Harassment due to sexual minority status: Experiences of harassment in the past year because of their sexual orientation

Self-concept: Identity subscale of the Psychosocial Maturity Inventory (Greenberger, 1976) includes questions addressing self-esteem and coherence of self-concept $(\alpha=.77 ; \alpha=.84$ for sexual minority youth) Self-regulation: both primary caregiver's and youths' reported selfcontrol from the subscale of the Social Skills Rating System (Gresham \& Elliot, 1990) (Maternal $\alpha=.83, .87$; Adolescent $\alpha=.74, .68$ )

Friendship quality: Perception of friendship quality with a best friend based on Friendship Quality Questionnaire (Parker \& Asher, 1993) $(\alpha=.92 ; .85$ for sexual minority youth)

Parental support: Scale assessing the youth's perceptions of their primary caregiver's caring and attentive behavior, with higher scores reflecting greater maternal warmth $(\alpha=.92 ; .90$ for sexual minority youth)

Quality of the school environment: Latent factor that combined school attachment $(\alpha=.76)$, teacher bonding $(\alpha=.61)$, and negative attitudes toward school $(\alpha=69)$. The subscales were drawn from the What My School is Like Questionnaire, adapted from the New Hope Study (Duncan, Huston, \& Weisner, 2007)

Sense of belonging: The Psychological subscale of the Sense of Belonging Instrument (Hagerty \& Patusky, 1995) $\alpha=.94$ for heterosexuals; $\alpha=.94$ for lesbians 


\begin{tabular}{ll}
\hline Study & Sample characteristics \\
\hline 17. McLaren et al. (2007) & Age: $M=39.02$ \\
& Relationship status: $41 \%$ gay men/23\% \\
& heterosexual men were single, $48 \%$ \\
& gay men/68\% heterosexual men were \\
& married or in a committed relationship, \\
& $10 \%$ gay men/9\% heterosexual men \\
& were separated or divorced, and $1 \%$ of \\
& gay men/0\% of heterosexual men were \\
& widowed \\
Education: $64 \%$ gay men/51\% heterosex- & ual men had a university degree \\
& Residence: $73 \%$ gay men/63\% heterosex- \\
& ual men leaved in an urban setting; $27 \%$ \\
gay men/37\% heterosexual men leaved & in a rural setting Income: heterosexual \\
men had a higher average income than & gay men
\end{tabular}

18. McLaughlin et al. (2012)

19. McNair et al. (2005)

20. Mereish et al. (2019) Age: $10-18$ years (26.2\% in Grade 6, $21.6 \%$ in Grade $8,27.8 \%$ in Grade 10 , $22.1 \%$ in Grade 12 )

Gender: $51.7 \%$ female, $47.2 \%$ male

21. Miller and Irvin (2016)

Education: $52 \%$ enrolled or completed college, $48 \%$ no college older cohort (mid-age cohort) from rural and remote areas

\section{Measures for mediator(s)}

Sense of belonging: The Psychological subscale of the Sense of Belonging Instrument (Hagerty \& Patusky, 1995) $\alpha=.95$ heterosexuals; $\alpha=.96$ gay males

Exposure to adversity: Aggregate dichotomous variable based on whether respondents scored positively on any of the following: Single item on childhood physical abuse by caregivers; single item on childhood sexual abuse from caregivers; 2 items assessing housing-related adversity; 3 items on intimate partner violence

Two subsamples included: younger cohort/

Age: 22-27 (younger cohort), 50-55 years

Residence: random sampling from Australian population register; oversampling

\section{Stress: The Perceived Stress Questionnaire for Younger Women} (PSQYW, Bell \& Lee, 2002) assesses self-reported stress on 10 items from five life domains

Abuse: Single item on childhood or adulthood physical, mental, emotional or sexual abuse or violence

Social support: The degree of social support was assessed by a modified version of the Medical Outcomes Study (MOS) Social Support Scale (Sherbourne \& Stewart, 1991). Respondents were asked "How often is each of the following kinds of support available to you if you need it?", with six items to assess social support in five dimensions: emotional support, information support, tangible support, positive social interaction and affectionate support

Cyber victimization: assessed with one item: "During the past 12 months, how often have you been electronically bullied by someone?"

Bias-based victimization: assessed with single item: "During the past 12 months, how often were you bullied for any of the following reasons? race, ethnicity, or national origin; religion; gender; because you are gay, lesbian, or bisexual, or someone thought you were; a physical or mental disability; because of your language or accent; and any other reason $(\alpha .0 .71)$

Type of victimization: Measured with three items addressing sexual abuse by a partner, threats of physical abuse by a partner and physical abuse by a partner

Emotional support: Single item: "How often do you get the social and emotional support you need?" 


\begin{tabular}{ll}
\hline Study & Sample characteristics \\
\hline $\begin{array}{l}\text { 22. Needham and Austin } \\
\text { (2010) }\end{array}$ & Age: $18-26$ years at wave 3, \\
$M=21.8$ years \\
Gender: $51 \%$ females, $49 \%$ males
\end{tabular}

23. Oginni et al. (2018)

24. Pakula et al. (2016)

25. Pearson and Wilkinson (2013)

26. Przedworski et al. (2015)
Age: $M=25.95$

Gender: All male sample

Ethnicity: tribe: $77.45 \%$ Yoruba, $30.25 \%$ other

Marital Status: Gay: $87.7 \%$ never married, $12.3 \%$ married. Heterosexual: $93.8 \%$ never married, $6.2 \%$ married

Age: $27.5 \% 18-29$ years, $22.5 \%$ 30-39 years, $25.7 \%$ 40-49 years, $24.4 \%$ 50-59 years

Gender: $50.1 \%$ females, $49.9 \%$ males

Education: $9.3 \%$ less than secondary school, $17.6 \%$ secondary school, $8.7 \%$ some post-secondary education, $64.3 \%$ post-secondary education

Racialized minority: $21.9 \%$ yes, $78.1 \%$ no Marital status: $37.4 \%$ single/widowed/ divorced, $62.6 \%$ married/common law Residence: $17 \%$ rural; $83 \%$ urban

Age: $12-18$ years (Grades 7 to 12 ) $M=15.63$ years

Gender: $51.9 \%$ females, and $48.1 \%$ males Ethnicity: 66\% non-Latino White, $15 \%$ Black, 11\% Latino, 3\% Asian/Pacific Islander, $3 \%$ other

Age: $M=23.8$ years

Gender: $50 \%$ females, $50 \%$ males

Ethnicity: 6.5\% Black, 6\% Hispanic, $14 \%$

East Asian, 10\% South Asian, 63\% White

Relationship status: $46 \%$ not in a relationship, $37 \%$ in a non-cohabitating relationship, $3 \%$ engaged, $14 \%$ married or living together
Measures for mediator(s)

Parental support: The measure combines respondents' reports of maternal and paternal emotional support during young adulthood. Support is the sum of responses to three items for each parent: how close respondents feel to their parent, whether their parent is warm and loving, and whether they enjoy doing things with their parent. $(\alpha=.83$ for the current residential mother support scale, $\alpha=.74$ for the current residential father support scale, $\alpha=.86$ for the previous residential mother support scale, and $\alpha=.89$ for the previous residential father support scale)

Family-related variables: included the marital status of the participants' parents; a single question assessing the experience of neglect by parents in childhood; gender atypical behavior in childhood and the response of parents to it

Resilience: assessed with the Positive Ideation subscale of the Positive and Negative Suicide Ideation Inventory (PANSI; Osman, Gutierrez, Kopper, Barrios, \& Chiros, 1998). $\alpha=.77$

Perceived life stress: Single item: "Thinking about the amount of stress in your life, would you say that most days are: not at all stressful, not very stressful or a bit stressful, quite a bit stressful, or extremely stressful?" Responses were recoded into a binary variable

Family relationships: Items asking questions about each of the respondents' relationship with their parents, e.g., "How close do you feel to your mother/father?". Responses about mothers and fathers were combined by calculating the mean response to all 5 items for each parent ( $\alpha=.84$ for mother, $\alpha=.89$ for father), and then took the mean of these two values for each respondent

Perceived parental closeness: The number of the shared activities the respondent participated in with their mother and father in the past 4 weeks: (1) went shopping, (2) played a sport, (3) attended religious services or a church-related event, (4) went to a movie, play, museum, concert, or sports event, and (5) worked on a project for school

Perceived family support: Five questions that asked respondents, "How much do you feel that: (1) your parents care about you? (2) people in your family understand you? (3) you want to leave home? (4) you and your family have fun together? (5) your family pays attention to you?" $(\alpha=.75)$

Social stressors: Two items from the Everyday Discrimination Scale (Clark, Coleman, \& Novak, 2004) were used (called names/insulted at least a few times a year; harassed or threatened at least a few times a year) and three items from the UCLA Loneliness Scale (Russell, 1996) (lack of companionship, feeling left out, and feeling isolated from others at least some of the time) 


\begin{tabular}{lll}
\hline Study & Sample characteristics & Measures for mediator(s) \\
\hline 27. Riley et al. (2016) & Age: LGB $M=18.38$ years, non-LGB & Stress: Perceived Stress Scale (PSS; Cohen \& Williamson, 1988) \\
& assessing experiences of stress; higher scores reflect greater cognitive \\
& Gender: 70.1\% females, 29.9\% males & appraisal of stressful life circumstances $(\alpha=.86)$ \\
& Ethnicity: LGB sample: $1.4 \%$ American & Coping styles: Brief COPE (Carver, 1997), assessing maladaptive and \\
& Indian/Alaskan, 9.6\% Asian, 2.7\% & adaptive coping styles. Six scales did not yield adequate reliability \\
Black/African-American, 11.0\% His- & and were not included in analyses. The scales included were: refram- \\
panic/Latino, 2.7\% other, 1.4\% Puerto & ing $(\alpha=.72)$; institution seeking $(\alpha=.83) ;$ denial $(\alpha=.73) ;$ religion \\
Rican, 71.2\% White & $(\alpha=.87) ;$ humor $(\alpha=.81)$; emotional support seeking $(\alpha=.75) ;$ sub- \\
Non-LGB sample: $0.5 \%$ American Indian/ & stance use $(\alpha=.86) ;$ and blame $(\alpha=.71)$
\end{tabular}

28. Robinson et al. (2013)

29. Rosario et al. (2014) Age: $17-25$ years $(M=20.6, S D=1.7)$ Gender: $64.4 \%$ females, $35.6 \%$ males Ethnicity: 93.9\% White
30. Safren and Heimberg Age: $16-21$ years, $M=18.2$ (1999)

31. Shenkman et al. (2019)
Gender: $51.9 \%$ females, $48.1 \%$ males

Ethnicity: LGB sample: $48 \%$ AfricanAmerican, 2\% Asian, 9\% Hispanic, 32\% White, 9\% biracial, 2\% Arabic

Non-LGB sample: 58\% AfricanAmerican, 40\% White, 2\% biracial

Education level: LGB sample $M=12.1$ $(S D=1.5)$; non-LGB sample $M=12.4$ $(S D=1.9)$

Living situation: LGB sample: $57 \%$ with parents; $16 \%$ with roommates; $11 \%$ other adult relative; $5 \%$ with grandparents; $5 \%$ with siblings; $4 \%$ on their own; $2 \%$ group or residential

Non-LGB sample: $50 \%$ with parents; $10 \%$ with roommates; $11 \%$ other adult relative; $2 \%$ with grandparents; $6 \%$ with siblings; $2 \%$ in foster care; $2 \%$ group or residential

Age: $M=28.46, S D=5.36$

Gender: $52.83 \%$ females, $47.17 \%$ males

Relationships: $54.8 \%$ no partner

Education: $61.2 \%$ had academic degree

Place of residence: $88.4 \%$ lived in the city

Place of birth: 94\% Israel, 6\% elsewhere

SES: $M=3.30, S D=0.94$ self-rated economic status
Victimization: Participants were asked whether they experienced specific forms of peer victimization during the previous 12 months. Parents also reported whether their child was bullied through name calling in wave 1 (no/yes).

Attachment: Scale assessing participants' degree of satisfaction with their relationship with their mother across nine items (e.g., general communication, affection, support, respect, shared time, interests) (Jaccard \& Dittus, 1991) $(\alpha=.94)$

Parental affection: Mothers reported their satisfaction with their relationship with their child across the same nine items completed by their children on the attachment measure $(\alpha=.94)$

Social support: Social Support Questionnaire (SSQ; Sarason, Levine, Basham, \& Sarason, 1983) yields scores for number of social supports, satisfaction with social support, and the degree to which a person perceives that he/she is satisfied with social support for help with problems $(\alpha=.98$ and .96$)$

Coping: The COPE (Carver, Scheier, \& Weintraub, 1989) assesses how respondents deal with stressful situations. The factor thought to be more relevant to LGB adolescents, coping through acceptance, was selected that has items that assess coping by accepting one's present circumstances, using restraint, and through positive reinterpretation and growth

Stress: Adolescent Perceived Events Scale (Compas et al., 1987), respondents indicated the occurrence of stressful events in the past 4 months and how desirable or undesirable they were on a scale. Event ratings were categorized as negative or positive events, yielding total scores for each category

Attachment avoidance was assessed on a subscale of the Experiences in Close Relationships questionnaire (ECR; Brennan, Clark, \& Shaver, 1998). Participants rated the extent to which they agreed with each statement on a 7-point scale on 18 items (e.g., "I don't feel comfortable opening up to other people in close relationships") $(\alpha=.91)$ 


\begin{tabular}{ll}
\hline Study & Sample characteristics \\
\hline 32. Sigurvinsdottir and & Age: $18-71$ years, $M=45.05$ years \\
Ullman (2016) & Ethnicity: Heterosexual women: 48\% \\
African-American, 36\% White, $2 \%$ & Asian, 7.90\% other, 13.10\% Hispanic, \\
& $5.9 \%$ multiracial \\
& Bisexual women: $36.8 \%$ African-Amer- \\
ican, $41.1 \%$ White, $2.1 \%$ Asian, $10.6 \%$ \\
other, $13.1 \%$ Hispanic, $9.5 \%$ multiracial \\
Employment: $43.40 \%$ of heterosexual \\
women and $37.9 \%$ of bisexual women \\
were employed \\
Education: Heterosexual women: $33.8 \%$ \\
college degree or higher, $43.4 \%$ some \\
college, $13.9 \%$ high school graduate, \\
$8.9 \%$ not completed high school \\
Bisexual women: $26.3 \%$ college degree or \\
higher, $37.9 \%$ some college, $23.2 \%$ high \\
school graduate, $12.6 \%$ not completed \\
high school \\
Income: Heterosexual women: \\
$38.1 \% \leq \$ 10,000,19 \% \$ 10,000-20,000 ;$ \\
$12.1 \% \$ 20,000-30,000,30.8 \% £ 30,000$ \\
Bisexual women: $47.3 \% \$ 10,000$ or less; \\
$22.6 \% \$ 10,000-20,000 ; 9.7 \% \$ 20,000-$ \\
30,$000 ; 20.5 \% \geq £ 30,000$ \\
Age: $19-25 y e a r s$
\end{tabular}

33. Smith et al. (2016)

Age: $19-25$ years

Gender: $59.9 \%$ females, $39.8 \%$ males, $0.3 \%$ transgender-identified

Ethnicity: 69\% Caucasian, 11.2\% Asian

American/Pacific Islander, 7.7\% Latino, 5.2\% Black/African-American, 6.9\% other

34. Spencer and Patrick (2009)

Age: Mean 21.34

Gender: $69.6 \%$ females, $30.4 \%$ males

Ethnicity: $88.2 \%$ non-Hispanic White, $11.8 \%$ other

Living arrangement: $9.5 \%$ alone, $12.4 \%$ with a domestic partner, $40.5 \%$ with non-relatives, $37.9 \%$ with relatives/other

Residence: $54.6 \%$ rural, $45.4 \%$ urban

Relationship status: $55.2 \%$ in a committed relationship, $45.1 \%$ other

Religion: 24.2\% Protestant, 28.1\% Catholic, $26.1 \%$ Jewish or other, $21.2 \%$ none

Employment: $85.9 \%$ college/university; $14.4 \%$ employed/other

35. Szalacha et al. (2017) Age: $25-30$ years

Education: $10 \%$ year 10 or less; $19.2 \%$ year 12 or equivalent; $26.6 \%$ Trade/ diploma; $34.2 \%$ university diploma; postgraduate degree $10.6 \%$

Income (AUD): $2 \% 15,999$ or less; $4.9 \%$ 16,000-36,999; $11.6 \%$ 37,000-51,999; $81.1 \% 52,000$ or greater

Relationship Status: $34.7 \%$ single; $41.6 \%$ married; $20.4 \%$ De facto; $2.7 \%$ separated/divorced

Parental Status: $68 \%$ no children; $32 \% 1$ or more children

Residence: $60.5 \%$ urban; $39.5 \%$ rural

Perceived social support: Social Support Questionnaire (SSQ; Sarason et al., 1983) (W1: $\alpha=.84$, W2: $\alpha=.87$, W3: $\alpha=.90$ )

Frequency of social contact: 5 questions asking how often a person comes into contact with informal social network members (Donald \& Ware, 1984). The composite score was based on the averaged items, with higher scores indicating greater frequency of social contact. (W1: $\alpha=.71$, W2: $\alpha=.71$, W3: $\alpha=.70$ )

Institutional betrayal: A modified version of the Institutional Betrayal Questionnaire (IBQ; Smith \& Freyd, 2013) measures institutional betrayal leading up to or after sexual assault. The instrument was given to participants who endorsed at least one at least one item on a sexual harassment and assault scale. Items include 7 questions about the role the institution played in the experience. Three additional items specifically examining the role of sexual orientation in institutional betrayal were added

Social support: Measured with the Medical Outcomes Study Social Support Survey (MOS-SSS; Sherbourne \& Stewart, 1991), which assesses several domains of social support including tangible support, emotional support, affective support, and positive support. Participants were asked how often each type of support was available to them if needed $(\alpha=.96)$

Personal mastery: The seven-item Personal Mastery scale (Pearlin \& Schooler, 1978) assessing the consciously controlled cognitive-affective aspects of sense of control $(\alpha=.79)$

Interpersonal violence: The Composite Abuse scale (Hegarty \& Valpied, 2007). Participants were asked whether or not in the previous three years they had experienced: physical abuse; severe physical abuse; emotional abuse; sexual abuse; and harassment. An item assessed IPV. Responses to the items were summed to create a measure of interpersonal violence experiences 


\begin{tabular}{ll}
\hline Study & Sample characteristics \\
\hline 36. Tate and Patterson & Age: $24.25-34.67(M=28.98, S D=1.75)$ \\
(2019) & Eender: $53.20 \%$ females, $46.80 \%$ males \\
& $22.8 \%$ African-American, $15.8 \%$ His- \\
panic, $8.8 \%$ other, $6.79 \%$ Asian descent, \\
3.4\% American Indian \\
Education: Ranged from 1 (eighth grade \\
or less) to 13 (completed post-baccalau- \\
reate professional education) $M=5.68$, \\
SD=2.19 \\
Income: Annual income ranged from $\$ 0$ to \\
\$1000 $(M=\$ 35.36 \mathrm{k}, S D=\$ 45.11 \mathrm{k}$, \\
Median $=\$ 30 \mathrm{k})$ \\
Age: Average age $=\sim 16$ years \\
Gender: $52 \%$ females, $48 \%$ males \\
Race/ethnicity: $42 \%$ White, $20 \%$ African- \\
Americans, $24 \%$ Hispanic, $14 \%$ other \\
origins (including Asian, Native Ameri- \\
can and other) \\
Location: $54 \%$ attended schools in subur- \\
ban communities, $29 \%$ in urban commu- \\
nities, $17 \%$ in rural communities \\
Bradley-Engen (2010) $18-23$ years $(M=20.02)$ \\
Ageasdale and \\
Gender: $46 \%$ females, $54 \%$ males \\
Ethnicity: $27.2 \%$ non-Hispanic White; \\
23.8 African-American; $24.8 \%$ Cuban; \\
$23.7 \%$ other Hispanic; $0.1 \%$ other race \\
Education: $80.4 \%$ graduated from high \\
school
\end{tabular}

Social stress: Measures of adolescent perceptions of prejudice by students (single item); witnessing/experiencing physical/sexual victimization experiences ( 3 items); family problems (single item about desire to run away from home); attempted/committed suicide of a close friend or family member were created

Social support: Single item that asked respondents their level of agreement with the statement "You feel socially accepted." Respondents were also asked how much they felt that parents, teachers, and friends care about them

Victimization: Inventory of traumatic events (Turner and Lloyd, 2003) modified to focus on interpersonal coercion and violence

Major discrimination events: total score from a five-item inventory (Williams, Yu, \& Jackson, 1997)

Daily discrimination: Items measuring minor but chronic and routine discrimination experience in daily life (Williams et al., 1997) $(\alpha=.85)$

Negative life events: measured by the total score from a 33-item checklist for a period of 12 months (Avison \& Turner, 1988). Some of these items were also asked for partners and friends/relatives and added to each respondent's total score

Chronic strains: Wheaton's (1994) measure modified to focus on life domains important for young adults: employment, school, residence, children, relationships with partners/parents, and general perceptions across domains

Family support: Measured by a scale that focused on emotional support by family (Turner \& Marino, 1994) $(\alpha=.91)$

Friend support: the summed score of eight items similar to family support items $(\alpha=.91)$

Optimism: Life Orientation Test (Scheier, Carver, \& Bridges, 1994) $(\alpha=.67)$

Mastery: Pearlin and Schooler's mastery scale (1978) $(\alpha=.73)$

Self-esteem: Rosenberg's self-esteem (1965) scale $(\alpha=.78)$

Mattering: Summed score from a five-item scale (Rosenberg \& McCullough, 1981) $(\alpha=.72)$

Fun-seeking orientation: The Fun-Seeking Subscale of Behavioral Activation System (BAS) (Gray, 1975) $(\alpha=.66)$

Relationship status: Dichotomous variable $(1=$ currently in a marital or dating relationship; $0=$ otherwise)

Number of sexual relationships: the lifetime total including opposite-sex and same-sex relationships

Early first sex: Dichotomous variable $(1=$ had sex before age 15 for men or 16 for women; $0=$ otherwise)

Parents'/friends' permissiveness of drug use: Summed scores from five-item scales ( $\alpha=.70$ for both parents' permissiveness and friends' permissiveness)

Friends' drug use: Summed score of a three-item scale $(\alpha=.78)$ 


\begin{tabular}{|c|c|c|}
\hline Study & Sample characteristics & Measures for mediator(s) \\
\hline 39. Wong et al. (2017) & $\begin{array}{l}\text { Age: } M=20.9 \text { years }(\mathrm{SD}=3.7) \\
\text { Gender: } 57.6 \% \text { females, } 39.3 \% \text { males } \\
\text { Education: } 0.5 \% \text { primary or below, } 5.9 \% \\
\text { secondary, } 91.8 \% \text { tertiary or above. } \\
93.7 \% \text { of participants were university } \\
\text { students } \\
\text { Dating status: } 73 \% \text { dating, } 3 \% \text { cohabitat- } \\
\text { ing, } 6.6 \% \text { broke up in past month, } 16.3 \% \\
\text { broke up in past year }\end{array}$ & $\begin{array}{l}\text { Dating violence: The Woman Abuse Screening Tool (WAST; Brown, } \\
\text { Lent, Schmidt, \& Sas, 2000) assessing physical, psychological, and } \\
\text { sexual violence at the most recent relationship } \\
\text { Sexual orientation concealment: Two items assessing how many family } \\
\text { and friends know about the respondents' sexual orientation }\end{array}$ \\
\hline $\begin{array}{l}\text { 40. Woodford et al. } \\
\text { (2014) }\end{array}$ & $\begin{array}{l}\text { Age: } M=23.1 \text { years } \\
\text { Gender: } 61.2 \% \text { females, } 38.8 \% \text { males } \\
\text { Ethnicity: } 72 \% \text { White }\end{array}$ & $\begin{array}{l}\text { Interpersonal mistreatment: Constructed measures assessing personal } \\
\text { and ambient hostility, incivility, and heterosexist harassment. Respond- } \\
\text { ents asked how often they had witnessed, heard, or knew about and } \\
\text { personally experienced each behavior on campus in the past year. Each } \\
\text { variable was dichotomized }\end{array}$ \\
\hline
\end{tabular}

Cronbach's alphas $(\alpha)$ presented in this table are from the sample of the study in question

\section{References}

Achenbach, T. M., \& Rescorla, L. A. (2001). ASEBA school-age forms \& profiles. University of Vermont, Research Center for Children, Youth and Families.

Achenbach, T. M., \& Rescorla, L. A (2003). Manual for the ASEBA adult forms \& profiles. University of Vermont, Research Center for Children, Youth and Families.

Almeida, J., Johnson, R. M., Corliss, H. L., Molnar, B. E., \& Azrael, D. (2009). Emotional distress among LGBT youth: The influence of perceived discrimination based on sexual orientation. Journal of Youth and Adolescence, 38, 1001-1014. https://doi.org/10.1007/ s10964-009-9397-9.

Argyriou, A., Goldsmith, K. A., Tsokos, A., \& Rimes, K. A. (2020). Psychosocial mediators of the relations between sexual orientation and depressive symptoms in a longitudinal sample of young people. Psychology of Sexual Orientation and Gender Diversity, 7, 142-153. https://doi.org/10.1037/sgd0000369.

Avison, W. R., \& Turner, R. J. (1988). Stressful life events and depressive symptoms: Disaggregating the effects of acute stressors and chronic strains. Journal of Health and Social Behavior, 29, 253-264. https://doi.org/10.2307/2137036.

Balsam, K. F., Rothblum, E. D., \& Beauchaine, T. P. (2005). Victimization over the life span: A comparison of lesbian, gay, bisexual, and heterosexual siblings. Journal of Consulting and Clinical Psychology, 73, 477-487. https://doi.org/10.1037/0022-006x.73.3.477.

Baron, R. M., \& Kenny, D. A. (1986). The moderator-mediator variable distinction in social psychological research: Conceptual, strategic, and statistical considerations. Journal of Personality and Social Psychology, 51, 1173-1182. https://doi. org/10.1037//0022-3514.51.6.1173.

Beck, A. T., Steer, R. A., \& Brown, G. K. (1996). Manual for the Beck Depression Inventory-II. Psychological Corporation.

Bell, S., \& Lee, C. (2002). Development of the Perceived Stress Questionnaire for young women. Psychology, Health and Medicine, 7, 191-200. https://doi.org/10.1080/13548500120116085.

Bonacich, P. (1987). Power and centrality: A family of measures. American Journal of Sociology, 92, 1170-1182.

Bostwick, W. B., Boyd, C. J., Hughes, T. L., \& McCabe, S. E. (2010). Dimensions of sexual orientation and the prevalence of mood and anxiety disorders in the United States. American Journal of Public Health, 100, 468-475. https://doi.org/10.2105/AJPH.2008.15294 2.
Brennan, K. A., Clark, C. L., \& Shaver, P. R. (1998). Self-report measurement of adult attachment: An integrative overview. In J. A. Simpson \& W. S. Rholes (Eds.), Attachment theory and close relationships (pp. 46-76). Guilford Press.

Brown, J. B., Lent, B., Schmidt, G., \& Sas, G. (2000). Application of the Woman Abuse Screening Tool (WAST) and WAST-short in the family practice setting. Journal of Family Practice, 49, 896-903.

Burns, R. A., Butterworth, P., \& Jorm, A. F. (2016). The long-term mental health risk associated with non-heterosexual orientation. Epidemiology and Psychiatric Sciences, 27, 74-83. https://doi. org/10.1017/s2045796016000962.

Burton, C. M., Marshal, M. P., Chisolm, D. J., Sucato, G. S., \& Friedman, M. S. (2013). Sexual minority-related victimization as a mediator of mental health disparities in sexual minority youth: A longitudinal analysis. Journal of Youth and Adolescence, 42, 394-402. https://doi.org/10.1007/s10964-012-9901-5.

Carver, C. S. (1997). You want to measure coping but your protocol's too long: Consider the brief COPE. International Journal of Behavioral Medicine, 4, 92-100. https://doi.org/10.1207/s1532 7558ijbm0401_6.

Carver, C. S., Scheier, M. F., \& Weintraub, J. K. (1989). Assessing coping strategies: A theoretically based approach. Journal of Personality and Social Psychology, 56, 267-283. https://doi. org/10.1037//0022-3514.56.2.267.

Carver, C. S., \& White, T. L. (1994). Behavioral inhibition, behavioral activation, and affective responses to impending reward and punishment: The BIS/BAS scales. Journal of Personality, 67, 319-333. https://doi.org/10.1037/0022-3514.67.2.319.

Cerin, E., Barnett, A., \& Baranowski, T. (2009). Testing theories of dietary behavior change in youth using the mediating variable model with intervention programs. Journal of Nutrition Education and Behavior, 41, 309-318. https://doi.org/10.1016/j. jneb.2009.03.129.

Chakraborty, A., McManus, S., Brugha, T. S., Bebbington, P., \& King, M. (2011). Mental health of the non-heterosexual population of England. British Journal of Psychiatry, 198, 143-148. https://doi. org/10.1192/bjp.bp.110.082271.

Clark, R., Coleman, A. P., \& Novak, J. D. (2004). Brief report: Initial psychometric properties of the Everyday Discrimination Scale in black adolescents. Journal of Adolescence, 27, 363-368. https:// doi.org/10.1016/j.adolescence.2003.09.004. 
Cohen, S., Kamarck, T., \& Mermelstein, R. (1983). A global measure of perceived stress. Journal of Health and Social Behavior, 24, 385-396. https://doi.org/10.2307/2136404.

Cohen, S., \& Williamson, G. M. (1988). Perceived stress in a probability sample of the United States. In S. Spacapan, \& S. Oskamp (Eds.), The social psychology of health (pp. 31-67). Sage.

Cole, D., \& Maxwell, S. E. (2003). Testing mediational models with longitudinal data: Questions and tips in the use of structural equation modelling. Journal of Abnormal Psychology, 112, 558-577. https://doi.org/10.1037/0021-843x.112.4.558.

Compas, B. E., Davies, G. E., Forsythe, C. J., \& Wagner, B. M. (1987). Assessment of major and daily stressful events during adolescence: The adolescent Perceived Events Scale. Journal of Consulting and Clinical Psychology, 55, 534-541. https://doi. org/10.1037/0022-006x.55.4.534.

Corliss, H. L., Austin, B., Roberts, A. L., \& Molnar, B. E. (2009). Sexual risk in "mostly heterosexual" young women: Influence of social support and caregiver mental health. Journal of Women's Health, 18, 2005-2010. https://doi.org/10.1089/jwh.2009.1488.

Corliss, H. L., Cochran, S. D., \& Mays, V. M. (2002). Reports of parental maltreatment during childhood in a United States populationbased survey of homosexual, bisexual, and heterosexual adults. Child Abuse and Neglect, 26, 1165-1178. https://doi.org/10.1016/ s0145-2134(02)00385-x.

Craig, S. L., \& Austin, A. (2016). The AFFIRM open pilot feasibility study: A brief affirmative cognitive behavioral coping skills group intervention for sexual and gender minority youth. Children and Youth Services Review, 64, 136-144. https://doi.org/10.1016/j. childyouth.2016.02.022.

Craig, S. L., McInroy, L., Austin, A., Smith, M., \& Engle, B. (2012). Promoting self-efficacy and self-esteem for multiethnic sexual minority youth: An evidence-informed intervention. Journal of Social Service Research, 38, 688-698. https://doi.org/10.1080/01488 376.2012.718194.

Derogatis, L. R. (1993). BSI brief symptom inventory: Administration, scoring, and procedures manual (4th ed.). National Computer Systems.

Donahue, K. L., Långström, N., Lundström, S., Lichtenstein, P., \& Forsman, M. (2017). Familial factors, victimization, and psychological health among sexual minority adolescents in Sweden. American Journal of Public Health, 107, 322-328. https://doi. org/10.2105/ajph.2016.303573.

Donald, C. A., \& Ware, J. E. (1984). The measurement of social support. Research in Community and Mental Health, 4, 325-370.

Duncan, G., Huston, A., \& Weisner, T. (2007). Higher ground: New hope for working families and their children. Russell Sage Foundation.

Dunn, G., Emsley, R., Liu, H. H., \& Landau, S. (2013). Integrating biomarker information within trials to evaluate treatment mechanisms and efficacy for personalised medicine. Clinical Trials, 10, 709-719. https://doi.org/10.1177/1740774513499651.

Effective Public Health Practice Project. (2009). Quality assessment tool for quantitative studies. Retrieved from http://www.ephpp .ca/tools.html.

Emsley, R., Dunn, G., \& White, I. R. (2010). Mediation and moderation of treatment effects in randomised controlled trials of complex interventions. Statistical Methods in Medical Research, 19, 237-270. https://doi.org/10.1177/0962280209105014.

Frisell, T., Lichtenstein, P., Rahman, Q., \& Långström, N. (2009). Psychiatric morbidity associated with same-sex sexual behavior: influence of minority stress and familial factors. Psychological Medicine, 40, 315-324. https://doi.org/10.1017/s003329170 9005996.

Frost, D. M., \& LeBlanc, A. J. (2014). Nonevent stress contributes to mental health disparities based on sexual orientation: Evidence from a personal projects analysis. American Journal of
Orthopsychiatry, 84, 557-566. https://doi.org/10.1037/ort00 00024.

Goldberg, D., Bridges, K., Duncan-Jones, P., \& Grayson, D. (1988). Detecting anxiety and depression in general medical settings. British Medical Journal, 297, 897-899. https://doi.org/10.1136/ bmj.297.6653.897.

Goldsmith, K. A., Chalder, T. C., White, P. D., Sharpe, M., \& Pickles, A. (2018a). Measurement error, time lag, unmeasured confounding: Considerations for longitudinal estimation of the effect of a mediator in randomised clinical trials. Statistical Methods in Medical Research, 27, 1615-1633. https://doi.org/10.1177/09622 80216666111.

Goldsmith, K. A., MacKinnon, D. P., Chalder, T., White, P. D., Sharpe, M., \& Pickles, A. (2018b). Tutorial: The practical application of longitudinal structural equation mediation models in clinical trials. Psychological Methods, 23, 191-207. https://doi.org/10.1037/ met0000154.

Gray, J. A. (1975). Elements of a two-process theory of learning. Academic Press.

Greenberger, E., \& Bond, L. (1976). Technical manual for the Psychosocial Maturity Inventory. Program in Social Ecology, University of California, Irvine.

Gresham, F. M., \& Elliot, S. N. (1990). The social skills rating system. American Guidance Systems.

Hagerty, B. M. L., Lynch-Sauer, J., Patusky, K. L., \& Bouwsema, M. (1993). An emerging theory of human relatedness. Journal of Nursing Scholarship, 25, 291-295. https://doi.org/10.1111/j.1547-5069.1993. tb00262.x.

Hagerty, B. M. K., \& Patusky, K. (1995). Developing a measure of sense of belonging. Nursing Research, 44, 9-13. https://doi. org/10.1097/00006199-199501000-00003.

Hanel, P. H. P., \& Vione, K. C. (2016). Do student samples provide an accurate estimate of the general public? PLoS ONE, 11, e0168354. https://doi.org/10.1371/journal.pone.0168354.

Hatzenbuehler, M. L. (2009). How does sexual minority stigma "get under the skin"? A psychological mediation framework. Psychological Bulletin, 135, 707-730. https://doi.org/10.1037/a0016441.

Hatzenbuehler, M. L., McLaughlin, K. A., \& Nolen-Hoeksema, S. (2008). Emotion regulation and internalizing symptoms in a longitudinal study of sexual minority and heterosexual adolescents. Journal of Child Psychology and Psychiatry, 49, 1270-1278. https://doi.org/10.1111/j.1469-7610.2008.01924.x.

Hatzenbuehler, M. L., McLaughlin, K. A., \& Xuan, Z. (2012). Social networks and risk for depressive symptoms in a national sample of sexual minority youth. Social Science and Medicine, 75, 1184-1191. https://doi.org/10.1016/j.socscimed.2012.05.030.

Hays, R. D., Sherbourne, C. D., \& Mazel, R. M. (1993). The RAND 36-item health survey 1.0. Health Economics, 2, 217-227. https ://doi.org/10.1002/hec.4730020305.

Hegarty, K., \& Valpied, J. (2007). Composite abuse scale manual. Department of General Practice, University of Melbourne.

Hughes, T. L., Johnson, T. P., Steffen, A. D., Wilsnack, S. C., \& Everett, B. (2014). Lifetime victimization, hazardous, and depression among heterosexual and sexual minority women. LGBT Health, 1, 192-203. https://doi.org/10.1089/lgbt.2014.0014.

Imai, K., Keele, L., \& Tingley, D. (2010). A general approach to causal mediation analysis. Psychological Methods, 15, 309-334. https ://doi.org/10.1037/a0020761.

Jaccard, J., \& Dittus, P. (1991). Parent-teenager communication: Towards the prevention of unintended pregnancies. Springer.

Karam, F., Berard, A., Sheehy, O., Huneau, M.-C., Briggs, G., Chambers, C., ... OTIS Research Committee. (2012). Reliability and validity of the 4-item Perceived Stress Scale among pregnant women: Results from the OTIS antidepressants study. Research Nursing Health, 35, 363-375. https://doi.org/10.1002/nur.21482. 
King, M., Semlyen, J., Tai, S. S., Killaspy, H., Osborn, D., Popelyuk, D., \& Nazareth, I. (2008). A systematic review of mental disorder, suicide, and deliberate self-harm in lesbian, gay and bisexual people. BMC Psychiatry, 8, 70. https://doi.org/10.1186/1471-244x-8-70.

Kohout, F. J., Berkman, L. F., Evans, D. A., \& Cornoni-Huntley, J. (1993). Two shorter forms of the CES-D depression symptoms index. Journal of Aging and Health, 5, 179-193. https://doi. org/10.1177/089826439300500202.

Kovacs, M. (1992). Children's depression inventory manual. MultiHealth Systems.

Krueger, E. A., Meyer, I. H., \& Upchurch, D. M. (2018). Sexual orientation group differences in perceived stress and depressive symptoms among young adults in the United States. LGBT Health, 5 , 242-249. https://doi.org/10.1089/lgbt.2017.0228.

la Roi, C., Kretschmer, T., Dijkstra, J. K., Veenstra, R., \& Oldehinkel, A. J. (2016). Disparities in depressive symptoms between heterosexual and lesbian, gay, and bisexual youth in a Dutch cohort: The TRAILS Study. Journal of Youth and Adolescence, 5, 440-456. https://doi.org/10.1007/s10964-015-0403-0.

Lee, H., Hübscher, M., Moseley, G. L., Kamper, S. J., Traeger, A. C., Mansell, G., \& McAuley, J. H. (2015). How does pain lead to disability? A systematic review and meta-analysis of mediation studies in people with back and neck pain. Pain, 156, 988-997. https://doi.org/10.1097/j.pain.0000000000000146.

Leleux-Labarge, K., Hatton, A. T., Goodnight, B. L., \& Masuda, A. (2015). Psychological distress in sexual minorities: Examining the roles of self-concealment and psychological inflexibility. Journal of Gay \& Lesbian Mental Health, 19, 40-54. https://doi. org/10.1080/19359705.2014.944738.

Leung, C. M., Ho, S., Kan, C. S., Hung, C. H., \& Chen, C. N. (1993). Evaluation of the Chinese version of the Hospital Anxiety and Depression Scale. A cross-cultural perspective. International Journal of Psychosomatics, 40, 29-34.

Little, B. R. (1983). Personal projects a rationale and method for investigation. Environment and Behavior, 15, 273-309. https://doi. org/10.1177/0013916583153002.

Lovibond, S. H., \& Lovibond, P. F. (1995). Manual for the depression anxiety stress scales (2nd ed.). Psychology Foundation of Australia.

Lubans, D. R., Foster, C., \& Biddle, S. J. H. (2008). A review of mediators of behavior in interventions to promote physical activity among children and adolescents. Preventive Medicine, 47, 463470. https://doi.org/10.1016/j.ypmed.2008.07.011.

Lucassen, M. F. G., Merry, S. N., Hatcher, S., \& Frampton, C. M. A. (2015). Rainbow SPARX: A novel approach to addressing depression in sexual minority youth. Cognitive and Behavioral Practice, 22, 203-216. https://doi.org/10.1016/j.cbpra.2013.12.008.

Luk, J. W., Gilman, S. E., Haynie, D. L., \& Simons-Morton, B. G. (2018). Sexual orientation and depressive symptoms in adolescents. Pediatrics, 141, e20173309. https://doi.org/10.1542/ peds.2017-3309.

Luk, J. W., Gilman, S. E., Sita, K. R., Cheng, C., Haynie, D. L., \& Simons-Morton, B. G. (2019). Cyber behaviors among heterosexual and sexual minority youth: Subgroup differences and associations with health indicators. Cyberpsychology, 22, 315-324. https://doi.org/10.1089/cyber.2018.0408.

MacKinnon, D. P. (2001) Mediating variable. In: N. J. Smelser \& P. B. Baltes (Eds.). International encyclopedia of the social and behavioral sciences (pp. 9503-9507). Elsevier.

MacKinnon, D. P., \& Dwyer, J. H. (1993). Estimating mediated effects in prevention studies. Evaluation Review, 17, 144-158. https:// doi.org/10.1177/0193841x9301700202.

MacKinnon, D. P., Lockwood, C. M., Hoffman, J. M., West, S. G., \& Sheets, V. (2002). A comparison of methods to test mediation and other intervening variable effects. Psychological Methods, 7, 83-104. https://doi.org/10.1037/1082-989x.7.1.83.
MacKinnon, D. P., Lockwood, C. M., \& Williams, J. (2004). Confidence limits for the indirect effect: Distribution of the product and resampling methods. Multivariate Behavioral Research, 39, 99-128. https://doi.org/10.1207/s15327906mbr3901_4.

Mansell, G., Kamper, S. J., \& Kent, P. (2013). Why and how back pain interventions work: What can we find out? Best Practice \& Research Clinical Rheumatology, 27, 685-697. https://doi. org/10.1016/j.berh.2013.

Markus, M., Lindhout, I., Boer, F., Hoogendijk, T., \& Arrindell, W. (2003). Factors of perceived parental rearing styles: The EMBU$\mathrm{C}$ examined in a sample of Dutch primary school children. Personality and Individual Differences, 34, 503-520. https://doi. org/10.1016/s0191-8869(02)00090-9.

Marshal, M. P., Dietz, L. J., Friedman, M. S., Stall, R., Smith, H. A., McGinley, J., ... Brent, D. A. (2011). Suicidality and depression disparities between sexual minority and heterosexual youth: A meta-analytic review. Journal of Adolescent Health, 49, 115-123. https://doi.org/10.1016/j.jadohealth.2011.02.005.

Martin-Storey, A., \& August, E. G. (2016). Harassment due to gender nonconformity mediates the association between sexual minority identity and depressive symptoms. Journal of Sex Research, 53, 85-97. https://doi.org/10.1080/00224499.2014.980497.

Martin-Storey, A., \& Crosnoe, R. (2012). Sexual minority status, peer harassment, and adolescent depression. Journal of Adolescence, 35, 1001-1011. https://doi.org/10.1016/j.adolescenc e.2012.02.006.

McLaren, S. (2008). The interrelations between sexual orientation, sense of belonging, and dysphoria among Australian women. Women and Health, 43, 123-137. https://doi.org/10.1300/j013v 43n03_07.

McLaren, S., Jude, B., \& McLachlan, A. J. (2007). Sexual orientation, sense of belonging and depression in Australian men. International Journal of Men's Health, 6, 259-272. https://doi. org/10.3149/jmh.0603.259.

McLaughlin, K. A., Hatzenbuehler, M. L., Xuan, Z., \& Conron, K. J. (2012). Disproportionate exposure to early-life adversity and sexual orientation disparities in psychiatric morbidity. Child Abuse and Neglect, 36, 645-655. https://doi.org/10.1016/j.chiab u.2012.07.00.

McNair, R., Kavanagh, A., Agius, P., \& Tong, B. (2005). The mental health status of young adult and non-heterosexual Australian women. Australian and New Zealand Journal of Public Health, 29, 265-271. https://doi.org/10.1111/j.1467-842x.2005.tb007 66.x.

Mereish, E. H., Sheskier, M., Hawthorne, D. J., \& Goldbach, J. T. (2019). Sexual orientation disparities in mental health and substance use among Black American young people in the USA: Effects of cyber and bias-based victimisation. Culture, Health \& Sexuality, 21, 985-998. https://doi.org/10.1080/13691 058.2018 .153211$.

Meyer, I. H. (2003). Prejudice, social stress, and mental health in lesbian, gay, and bisexual populations: Conceptual issues and research evidence. Psychological Bulletin, 129, 674-697. https ://doi.org/10.1037/0033-2909.129.5.674.

Miller, B., \& Irvin, J. (2016). Invisible scars: Comparing the mental health of LGB and heterosexual intimate partner violence survivors. Journal of Homosexuality, 64, 1180-1195. https://doi. org/10.1080/00918369.2016.1242334.

Moher, D., Liberati, A., Tetzlaff, J., \& Altman, D. G. (2009). Preferred reporting items for systematic reviews and meta-analyses: The PRISMA statement. Annals of Internal Medicine, 151, 264-269. https://doi.org/10.1371/journal.pmed.1000097.

Needham, B. L., \& Austin, E. L. (2010). Sexual orientation, parental support, and health during the transition to young adulthood. Journal of Youth and Adolescence, 39, 1189-1198. https://doi. org/10.1007/s10964-010-9533-6. 
Nolen-Hoeksema, S., \& Morrow, J. (1991). A prospective study of depression and distress following a natural disaster: The 1989 Loma Prieta earthquake. Journal of Personality and Social Psychology, 61, 105-121. https://doi. org/10.1037//0022-3514.61.1.115.

Oginni, O. A., Mosaku, K. S., Mapayi, B. M., Akinsulore, A., \& Afolabi, T. O. (2018). Depression and associated factors among gay and heterosexual male university students in Nigeria. Archives of Sexual Behavior, 47, 119-1132. https://doi.org/10.1007/s1050 8-017-0987-4.

Orpinas P. (1993). Modified depression scale. University of Texas Health Science Center at Houston.

Osman, A., Gutierrez, P. M., Kopper, B. A., Barrios, F. X., \& Chiros, C. E. (1998). The Positive and Negative Suicide Ideation Inventory: Development and validation. Psychological Reports, 82, 783-793. https://doi.org/10.2466/pr0.1998.82.3.783.

Pachankis, J. E. (2007). The psychological implications of concealing a stigma: A cognitive-affective-behavioral model. Psychological Bulletin, 133, 328-345. https://doi. org/10.1037/0033-2909.133.2.328.

Pachankis, J. E., Hatzenbuehler, M. L., Rendina, H. J., Safren, S. A., \& Parsons, J. T. (2015). LGB-affirmative cognitive-behavioral therapy for young adult gay and bisexual men: A randomized controlled trial of a transdiagnostic minority stress approach. Journal of Consulting and Clinical Psychology, 83, 875-889. https://doi. org/10.1037/ccp0000037.

Pachankis, J. E., McConocha, E. M., Clark, K. A., Wang, K., Behari, K., Fetzner, B. K., ... Lehavot, K. (2020). A transdiagnostic minority stress intervention for gender diverse sexual minority women's depression, anxiety, and unhealthy alcohol use: A randomized controlled trial. Journal of Consulting and Clinical Psychology, 88, 613-630. https://doi.org/10.1037/ccp0000508.

Pakula, B., Carpiano, R. M., Ratner, P. A., \& Shoveller, J. A. (2016). Life stress as a mediator and community belonging as a moderator of mood and anxiety disorders and co-occurring disorders with heavy drinking of gay, lesbian, bisexual, and heterosexual Canadians. Social Psychiatry and Psychiatric Epidemiology, 51, 1181-1192. https://doi.org/10.1007/s00127-016-1236-1.

Pakula, B., \& Shoveller, J. A. (2013). Sexual orientation and self-reported mood disorder diagnosis among Canadian adults. BMC Public Health, 13, 209. https://doi.org/10.1186/1471-2458-13-209.

Parker, J. G., \& Asher, S. R. (1993). Friendship and friendship quality in middle childhood: Links with peer group acceptance and feelings of loneliness and social dissatisfaction. Developmental Psychology, 29, 611-621. https://doi.org/10.1037/0012-1649.29.4.611.

Pearlin, L. I., \& Schooler, C. (1978). The structure of coping. Journal of Health and Social Behavior, 19, 2-21. https://doi. org/10.2307/2136319.

Pearson, J., \& Wilkinson, L. (2013). Family relationships and adolescent well-being: Are families equally protective for same-sex attracted youth? Journal of Youth and Adolescence, 42, 376-393. https:// doi.org/10.1007/s10964-012-9865-5.

Penza-Clyve, S., \& Zeman, J. (2002). Initial validation of the Emotion Expression Scale for Children (EESC). Journal of Clinical Child and Adolescent Psychology, 31, 540-547. https://doi. org/10.1207/153744202320802205.

Pickles, A., Harris, V., Green, J., Aldred, X., McConachie, H., Slomins, V., ... PACT Consortium. (2015). Treatment mechanism in the MRC preschool autism communication trial: Implications for study design and parent-focussed therapy for children. Journal of Child Psychology and Psychiatry, 56, 162-170. https://doi. org/10.1111/jcpp.12291.

Pilkonis, P. A., Choi, S. W., Reise, S. P., Stover, A. M., Riley, W. T., \& Cella, D. (2011). Item banks for measuring emotional distress from the Patient-Reported Outcomes Measurement Information
System (PROMIS): Depression, anxiety, and anger. Assessment, 18, 263-283. https://doi.org/10.1177/1073191111411667.

Plöderl, M., \& Tremblay, P. (2015). Mental health of sexual minorities. A systematic review. International Review of Psychiatry, 27(5), 367-385. https://doi.org/10.3109/09540261.2015.1083949.

Przedworski, J. M., Dovidio, J. F., Hardeman, R. R., Phelan, S. M., Burke, S. E., Ruben, M. A., ... Yeazel, M. W. (2015). A comparison of the mental health and well-being of sexual minority and heterosexual first-year medical students: A report from the medical student CHANGE Study. Academic Medicine, 90, 652-659. https://doi.org/10.1097/avm.0000000000000658.

Radloff, L. S. (1977). The CES-D scale: A self-report depression scale for research in the general population. Applied Psychological Measurement, 1, 385-401. https://doi.org/10.1177/0146621677 00100306.

Riley, T. J., Kirsch, A. C., Shapiro, J. B., \& Conley, C. S. (2016). Examining stress and coping as a mediator for internalizing symptomatology: A comparison between sexual minority and majority firstyear college students. Journal of Adolescence, 49, 124-133. https ://doi.org/10.1016/j.adolescence.2016.03.005.

Roberts, A. L., Austin, S. B., Corliss, H. L., Vandermorris, A. K., \& Koenen, K. C. (2010). Pervasive trauma exposure among U.S. sexual orientation minority adults and risk of posttraumatic stress disorder. American Journal of Public Health, 100, 2433-2441. https://doi.org/10.2105/AJPH.2009.168971.

Robinson, J. P., Espelage, D. L., \& Rivers, I. (2013). Developmental trends in peer victimization and emotional distress in LGB and heterosexual youth. Pediatrics, 131, 423-430. https://doi. org/10.1542/peds.2012-2595.

Rosario, M., Reisner, S. L., Corliss, H. L., Wypij, D., Frazier, A. L., \& Austin, S. B. (2014). Disparities in depressive distress by sexual orientation in emerging adults: The roles of attachment and stress paradigms. Archives of Sexual Behavior, 43, 901-916. https://doi. org/10.1007/s10508-013-0129-6.

Rosenberg, M. (1965). Society and the adolescent self-image. Princeton University Press.

Rosenberg, M., \& McCullough, B. C. (1981). Mattering: Inferred significance and mental health among adolescents. Research in Community and Mental Health, 2, 163-182.

Russell, D. (1996). UCLA Loneliness Scale (Version 3): Reliability, validity, and factor structure. Journal of Personality Assessment, 66, 20-40. https://doi.org/10.1207/s15327752jpa6601_2.

Safren, S. A., \& Heimberg, R. G. (1999). Depression, hopelessness, suicidality, and related factors sexual minority and heterosexual adolescents. Journal of Consulting and Clinical Psychology, 67, 859-866. https://doi.org/10.1037//0022-006x.67.6.859.

Sarason, I. G., Levine, H. M., Basham, R. B., \& Sarason, B. R. (1983). Assessing social support: The Social Support Questionnaire. Journal of Personality and Social Psychology, 44, 127-139. https ://doi.org/10.1037/0022-3514.44.1.127.

Scheier, M. F., Carver, C. S., \& Bridges, M. W. (1994). Distinguishing optimism from neuroticism (and trait anxiety, self-mastery, and self- esteem): A reevaluation of the Life Orientation Test. Journal of Personality and Social Psychology, 67, 1063-1078. https://doi. org/10.1037//0022-3514.67.6.1063.

Schuster, T. L., Kessler, R. C., \& Aseltine, R. H., Jr. (1990). Supportive interactions, negative interactions, and depressed mood. American Journal of Community Psychology, 18, 423-438. https://doi. org/10.1007/bf00938116.

Shenkman, G., Stein, Y., \& Bos, H. (2019). The mediating role of attachment avoidance in the association between sexual orientation and mental health. Journal of Homosexuality, 20, 1-15. https://doi. org/10.1080/00918369.2019.1656507.

Sherbourne, C. D., \& Stewart, A. L. (1991). The MOS Social Support Survey. Social Science and Medicine, 32, 705-714. https://doi. org/10.1016/0277-9536(91)90150-b. 
Sigurvinsdottir, R., \& Ullman, S. E. (2016). Sexual assault in bisexual and heterosexual women survivors. Journal of Bisexuality, 16, 163-180. https://doi.org/10.1080/15299716.2015.1136254.

Smith, C. P., Cunningham, S. A., \& Freyd, J. J. (2016). Sexual violence, institutional betrayal, and psychological outcomes for LGB college students. Translational Issues in Psychological Science, 2, 351-360. https://doi.org/10.1037/tps0000094.

Smith, C. P., \& Freyd, J. J. (2013). Dangerous safe havens: Institutional betrayal exacerbates sexual trauma. Journal of Traumatic Stress, 26, 119-124. https://doi.org/10.1002/jts.21778.

Sobel, M. E. (1982). Asymptotic confidence intervals for indirect effects in structural equation models. Sociological Methodology, 13, 290-312. https://doi.org/10.2307/270723.

Spencer, S. M., \& Patrick, J. H. (2009). Social support and personal mastery as protective resources during emerging adulthood. Journal of Adult Development, 16, 191-198. https://doi.org/10.1007/ s10804-009-9064-0.

Szalacha, L. A., Hughes, T. L., McNair, R., \& Loxton, D. (2017). Mental health, sexual identity, and interpersonal violence: Findings from the Australian Longitudinal Women's Health Study. BMC Women's Health, 17, 94. https://doi.org/10.1186/s12905-017-0452-5.

Tate, D. P., \& Patterson, C. J. (2019). Sexual orientation, relationships with parents, stress, and depressive symptoms among adults. Journal of GLBT Family Studies, 15, 256-271. https://doi. org/10.1080/1550428x.2018.1486263.

Teasdale, B., \& Bradley-Engen, M. S. (2010). Adolescent same-sex attraction and mental health: The role of stress and support. Journal of Homosexuality, 57, 287-309. https://doi.org/10.1080/00918 360903489127.

Timmins, L., Rimes, K. A., \& Rahman, Q. (2018). Minority stressors, rumination, and psychological distress in monozygotic twins discordant for sexual minority status. Psychological Medicine, 48, 1705-1712. https://doi.org/10.1017/s003329171700321x.

Turner, R. J., \& Lloyd, D. A. (2003). Cumulative adversity and drug dependence in young adults: Racial/ethnic contrasts. Addiction, 98, 305-315. https://doi.org/10.1046/j.1360-0443.2003.00312.x.

Turner, R. J., \& Marino, F. (1994). Social support and social structure: A descriptive epidemiology. Journal of Health and Social Behavior, 35, 193-212. https://doi.org/10.2307/2137276.

Ueno, K. (2010). Mental health differences between young adults with and without same-sex contact: A simultaneous examination of underlying mechanisms. Journal of Health and Social Behavior, 51, 391-407. https://doi.org/10.1177/0022146510386793.
US Department of Health and Human Services. (2014). Quality assessment tool for observational cohort and cross-sectional studies. Retrieved from https://www.nhlbi.nih.gov/healthpro/guidelines/ indevelop/cardiovascularriskreduction/tools/cohort.

VanderWeele, T. J., \& Vansteelandt, S. (2009). Conceptual issues concerning mediation, interventions and composition. Statistics and its Interface, 2, 457-468. https://doi.org/10.4310/sii.2009.v2.n4. a7.

Watkings, P. C., Vache, K., Verney, S. P., Muller, S., \& Matthews, A. (1996). Unconscious mood-congruent memory bias in depression. Journal of Abnormal Psychology, 105, 34-41. https://doi. org/10.1037//0021-843x.105.1.34.

Wheaton, B. (1994). Sampling the Stress Universe. In W. Avison \& I. Gotlib (Eds.) Stress and mental health: Contemporary issues and prospects for the future (pp. 77-114). Plenum.

Williams, D. R., Yu, Y., \& Jackson, J. S. (1997). Racial differences in physical and mental health: Socioeconomic status, stress and discrimination. Journal of Health Psychology, 2, 335-351. https ://doi.org/10.1177/135910539700200305.

Wong, J. Y., Choi, E. P., Lo, H. H., Wong, W., Chio, J. H., Choi, A. W., \& Fong, D. Y. (2017). Dating violence, quality of life and mental health in sexual minority populations: A path analysis. Quality of Life Research, 26, 959-968. https://doi.org/10.1007/ s11136-016-1415-2.

Woodford, M. R., Han, Y., Craig, S., Lim, C., \& Matney, M. M. (2014). Discrimination and mental health among sexual minority college students: The type and form of discrimination does matter. Journal of Gay \& Lesbian Mental Health, 18, 142-163. https:// doi.org/10.1080/19359705.2013.833882.

Zietsch, B. P., Verweij, K. J., Bailey, J. M., Wright, M. J., \& Martin, N. G. (2011). Sexual orientation and psychiatric vulnerability: A twin study of neuroticism and psychoticism. Archives of Sexual Behavior, 40, 133-142. https://doi.org/10.1007/s1050 8-009-9508-4.

Zung, W. W. (1965). A self-rating depression scale. Archives of General Psychiatry, 12, 63-67. https://doi.org/10.1001/archp syc.1965.01720310065008.

Publisher's Note Springer Nature remains neutral with regard to jurisdictional claims in published maps and institutional affiliations. 